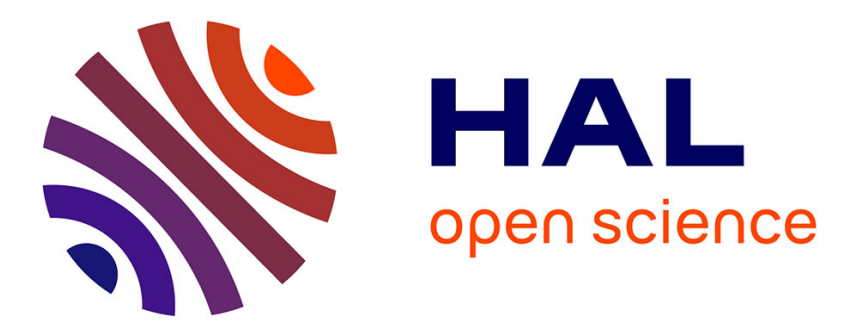

\title{
Lanthanum manganite perovskite ceramic powders for CO2 splitting: Influence of Pechini synthesis parameters on sinterability and reactivity
}

Julien Jouannaux, Anita Haeussler, Martin Drobek, Andre Ayral, Stéphane Abanades, Anne Julbe

\section{To cite this version:}

Julien Jouannaux, Anita Haeussler, Martin Drobek, Andre Ayral, Stéphane Abanades, et al.. Lanthanum manganite perovskite ceramic powders for CO2 splitting: Influence of Pechini synthesis parameters on sinterability and reactivity. Ceramics International, 2019, 10.1016/j.ceramint.2019.05.075 . hal-02146514

\section{HAL Id: hal-02146514 \\ https://hal.umontpellier.fr/hal-02146514}

Submitted on 12 Nov 2020

HAL is a multi-disciplinary open access archive for the deposit and dissemination of scientific research documents, whether they are published or not. The documents may come from teaching and research institutions in France or abroad, or from public or private research centers.
L'archive ouverte pluridisciplinaire HAL, est destinée au dépôt et à la diffusion de documents scientifiques de niveau recherche, publiés ou non, émanant des établissements d'enseignement et de recherche français ou étrangers, des laboratoires publics ou privés. 
Lanthanum manganite perovskite ceramic powders for $\mathrm{CO}_{2}$ splitting: Influence of Pechini synthesis parameters on sinterability and reactivity

\author{
Julien JOUANNAUX ${ }^{1}$, Anita HAEUSSLER ${ }^{2}$, Martin DROBEK ${ }^{1}$, André AYRAL ${ }^{1}$, \\ Stéphane ABANADES ${ }^{2}$, Anne JULBE ${ }^{1 *}$ \\ ${ }^{1}$ Institut Européen des Membranes, IEM - UMR5635, ENSCM, CNRS, Univ Montpellier, \\ Place Eugène Bataillon, 34095 Montpellier cedex 5, France \\ 2 Processes, Materials and Solar Energy Laboratory, CNRS-PROMES, 7 Rue du Four \\ Solaire, 66120 Font-Romeu, France \\ * Contact: anne.julbe@ umontpellier.fr; Tel.: +33-046-714-9142
}

\begin{abstract}
:
Solar-driven thermochemical splitting of $\mathrm{CO}_{2}$ and $\mathrm{H}_{2} \mathrm{O}$ using the redox properties of ceramic oxides is a promising option for the massive production of synthetic fuels without greenhouse gas emission and with complete recycling of chemical intermediates. The development of relevant redox oxides pairs with optimum formulation and design is a real challenge for the implementation of this attractive energy production technology. Redox oxide pairs offering both high redox properties and easy shaping ability have thus to be identified. In this work a series of $(\mathrm{La}, \mathrm{Sr})(\mathrm{Mn}, \mathrm{X}) \mathrm{O}_{3}$ and $(\mathrm{La}, \mathrm{Ca})(\mathrm{Mn}, \mathrm{X}) \mathrm{O}_{3}$ powders with $\mathrm{X}=\mathrm{Al}, \mathrm{Mg}, \mathrm{Ga}$ or $\mathrm{Cr}$ have been prepared by Pechini-derived methods. In particular the impact of the synthesis parameters and type of dopant $(\mathrm{X})$ on the physicochemical characteristics and reactivity of the powders (sinterability and redox properties) has been investigated. The results offer a relevant control over the synthesis / structure / properties relationships of the perovskite powders as crucial parameters targeting both the best perovskite formulations and design to be possibly integrated in solar thermochemical reactors.
\end{abstract}

Keywords: Ceramic materials; Perovskites; Sintering; Thermochemical splitting 


\section{Introduction}

Hydrogen, syngas, and derived synthetic fuels are environmentally attractive energy carriers and sustainable transportation fuels, having the potential to displace their fossil analogues. They can be produced from a variety of sources, including renewable ones such as wind, sun, or biomass. In particular, harnessing of the huge energy potential of solar radiation and its effective conversion to chemical energy carriers is a subject of primary technological interest [1]. Hence, using solar power to produce the highly-demanded reaction intermediate, syngas, directly from $\mathrm{H}_{2} \mathrm{O}$ and captured $\mathrm{CO}_{2}$, provides a promising path towards sustainable energy conversion into valuable solar fuels [2,3]. The so-called solar-driven thermochemical splitting of $\mathrm{CO}_{2}$ and $\mathrm{H}_{2} \mathrm{O}$ involves redox reactions of metal oxides in 2-step cycles. In the first step driven by solar thermal energy, metal oxide reduction generates an active oxygen-deficient material with pure oxygen release, according to reaction (1). In the second step, the re-oxidation of the active redox material by $\mathrm{H}_{2} \mathrm{O}$ and/or $\mathrm{CO}_{2}$ produces $\mathrm{H}_{2}$ and/or $\mathrm{CO}$ according to reaction (2).

$$
\begin{aligned}
& M_{x} O_{y} \rightarrow M_{x} O_{y-\delta}+\frac{\delta}{2} O_{2} \\
& M_{x} O_{y-\delta}+\delta \mathrm{CO}_{2}\left(\mathrm{H}_{2} \mathrm{O}\right) \rightarrow M_{x} O_{y}+\delta C O\left(H_{2}\right)
\end{aligned}
$$

It must be underlined, that such strategy for syngas production features several advantages: $i$ ) the maximum temperature of the cycle (generally $\sim 1400^{\circ} \mathrm{C}$ ) is compatible with renewable concentrated solar thermal energy source; ii) $\mathrm{H}_{2} \mathrm{O}, \mathrm{CO}_{2}$ and solar heat are the only inputs, while $\mathrm{H}_{2} / \mathrm{CO}$ and oxygen are the only reaction outputs with a remaining part of unconverted $\mathrm{H}_{2} \mathrm{O}$ or $\mathrm{CO}_{2}$; iii) $\mathrm{H}_{2} / \mathrm{CO}$ and $\mathrm{O}_{2}$ are produced separately, thus avoiding any additional gas separation step at high temperatures; $i v$ ) the oxide is recycled in a closed cycle, making the process inherently renewable and pollution-free.

Typical redox oxide pairs used in thermochemical splitting are metal oxides based on either volatile (e.g. $\mathrm{ZnO} / \mathrm{Zn}$ and $\mathrm{SnO} 2 / \mathrm{SnO}[4])$ or non-volatile stoichiometric and non-stoichiometric redox pairs $(\mathrm{CeO} 2 / \mathrm{CeO} 2-\delta$ [5,6], $\mathrm{Fe} 3 \mathrm{O} 4 / \mathrm{FeO}$, ferrites [7-9], NiFe2O4 [10]). More exhaustive 
lists of relevant material formulations can be found in the literature [11-13]. Recently, nonstoichiometric ceramics with $\mathrm{ABO} 3-\delta$ perovskite structure attracted significant attention, thanks to their attractive redox properties, durability and reliability. Indeed, perovskites feature structural stability over a wide range of oxygen non-stoichiometry, high oxygen release ability and attractive oxygen transport properties (high reduction extent at moderately lower temperature than e.g. ceria). In addition they present mixed ionic-electronic conduction, good thermal stability at high temperature, and many possible cationic substitutions in both A and B sites for tuning their redox properties.

Perovskites formulations such as $\mathrm{La}_{0.5} \mathrm{Ca}_{0.5} \mathrm{MnO}_{3}$ (LCM) and $\mathrm{La}_{0.5} \mathrm{Sr}_{0.5} \mathrm{MnO}_{3}$ (LSM) with or without any dopant have been tested for either $\mathrm{H}_{2} \mathrm{O}$ or $\mathrm{CO}_{2}$ splitting [14-18]. Insertion of aluminum in the B site [19] was found to increase both $\mathrm{H}_{2}$ production and reaction kinetics, with constant production rate after 80 cycles. The insertion of $\mathrm{Ga}$ in the $\mathrm{B}$ site (limited to $30 \%$ due to its low solubility) [20] was found to increase the tolerance factor, with beneficial influence on the reduction rate. Nair and Abanades [21] pointed out that $\mathrm{Mg}$ as dopant in the B site does not increase the production rate but improves thermal stability. A detailed overview of the best performing perovskite formulations, with a special focus on their ability to produce solar fuel with high yield and stable performance was recently published by Haeussler et al. [13].

It should be pointed out that besides the detailed investigations on thermodynamic, crystallographic and redox properties of the most relevant ceramic powders, relatively few studies in the literature investigate the sinterability and shaping of these materials, as required for an optimum integration in thermochemical reactors. In fact, after considering the application of free powders in moving-bed solar-reactors [22-24], monolithic and shaped materials are now often considered as more attractive options for application in $\mathrm{CO}_{2}$ or $\mathrm{H}_{2} \mathrm{O}$ splitting [25-27]. Depending on the design required for the reactive materials in the solar reactor (pellet, foam, granulate, membrane), relevant synthesis and shaping methods have thus to be selected. In most cases, 
nanopowders (reactive for dry sintering) or liquid sols/suspensions (adapted for casting layers of the nanomaterial on porous supports) are recommended options to confer a high available specific surface area for the solid oxide/gas reaction, thus favoring both surface reactions and kinetic rate of the oxidation. When considering shaped structures, the addition of interconnected micrometric pores (e.g. using pores former) is usually advocated to facilitate the access/release of gases within the entire mass of the oxide structure. In contrast, reactive dense membranes should not exhibit any interconnected porosity in order to guaranty selective oxygen transport (mixed ionicelectronic conduction) through the material thickness.

Liquid phase Pechini-methods are particularly relevant for preparing either ceramic nanopowders or thin films with uniform composition and microstructure, even for complex material formulations [28,29]. For each given composition, the structure, microstructure and surface properties of the powders are key-parameters determining their reactivity for both sintering and redox reactions. In the present work, a series of $(\mathrm{La}, \mathrm{Sr})(\mathrm{Mn}, \mathrm{X}) \mathrm{O}_{3}$ and $(\mathrm{La}, \mathrm{Ca})(\mathrm{Mn}, \mathrm{X}) \mathrm{O}_{3}$ powders with $\mathrm{X}=\mathrm{Al}, \mathrm{Mg}, \mathrm{Ga}$ or $\mathrm{Cr}$ has been prepared using a Pechini-based method with two different sets of parameters. Doping A and B sites with a series of alkaline earth and transition metal cations, respectively, was carried out to evaluate their impact on powder sinterability, reactivity and cyclability during thermochemical $\mathrm{CO}_{2}$ splitting. The results of this structural and microstructural study aim to offer a possibility to tailor both the reactivity and sinterability of the selected perovskite powders as crucial parameters targeting both the best powder formulations and design for a relevant integration in thermochemical reactors. 


\section{Experimental}

\subsection{Chemicals}

Chemicals for the perovskites powder synthesis $\mathrm{La}\left(\mathrm{NO}_{3}\right)_{3} \cdot 6 \mathrm{H}_{2} \mathrm{O}(99.9 \%), \mathrm{Ca}\left(\mathrm{NO}_{3}\right)_{3} \cdot 4 \mathrm{H}_{2} \mathrm{O}(99 \%)$, $\mathrm{Mn}\left(\mathrm{NO}_{3}\right)_{3} .4 \mathrm{H}_{2} \mathrm{O}(98 \%), \quad \mathrm{Sr}\left(\mathrm{NO}_{3}\right)_{2}(99 \%), \mathrm{Al}\left(\mathrm{NO}_{3}\right)_{3} .9 \mathrm{H}_{2} \mathrm{O}(98 \%), \operatorname{Cr}\left(\mathrm{NO}_{3}\right)_{3} .9 \mathrm{H}_{2} \mathrm{O} \quad(98.5 \%)$, $\mathrm{Mg}\left(\mathrm{NO}_{3}\right) \cdot 6 \mathrm{H}_{2} \mathrm{O}$ (98-102\%), $\mathrm{Ga}\left(\mathrm{NO}_{3}\right)_{3} \cdot \mathrm{xH}_{2} \mathrm{O}(99.9 \%)$ and ethylene glycol (99\%) were all purchased from Alfa Aesar, while Citric acid (CA) (99\%) was obtained from Sigma-Aldrich.

\subsection{Material synthesis}

The perovskite powders were synthesized by a Pechini-derived method [28,29] based on the utilization of nitrate metal salts (M), citric acid (CA) as a chelating agent, and ethylene glycol (EG) as a complexing agent. Two different solution formulations with the following molar ratios: M:CA:EG = 1:1.5:1 (P1 method) and M:CA:EG = 1:5:20 (P2 method) have been applied. In a typical synthesis, the given quantity of metal nitrates was dissolved in water in the fixed mass ratio $\mathrm{M}: \mathrm{H}_{2} \mathrm{O}$ of $1: 6$.

LSM powders (with or without $\mathrm{Mg}$ or $\mathrm{Al}$ dopant) were first prepared by the P1 method. The mixture of nitrate salts and CA (CA:M = 1.5:1) was heated to $60{ }^{\circ} \mathrm{C}$ and stirred for $10 \mathrm{~min}$. Then, EG was added to the solution in the molar ratio $\mathrm{EG}: \mathrm{CA}=0.66: 1$.

In parallel, LSM and LCM powders were prepared by P2 method, in which large excess of CA was added to the metal salts solution (CA:M= 5:1). The mixture was heated to $60{ }^{\circ} \mathrm{C}$ and stirred for $10 \mathrm{~min}$. Then, a large excess of EG was added to the solution in the molar ratio EG:CA=4:1. For both methods, the final mixture was heated at $120{ }^{\circ} \mathrm{C}$ until a viscous colored sol was obtained, which was further heated at $250{ }^{\circ} \mathrm{C}$ for $2 \mathrm{~h}$ to form a polymeric resin (polyesterification step). The as-obtained resin was crushed using an agate mortar and subsequently treated in successive thermal treatment steps in air atmosphere: 1) $600{ }^{\circ} \mathrm{C}$ for $1 \mathrm{~h}$ with a $3{ }^{\circ} \mathrm{C} / \mathrm{min}$ ramp yielding a 
porous ceramic powder, 2) $1400{ }^{\circ} \mathrm{C}$ for $1 \mathrm{~h}$ with a $5{ }^{\circ} \mathrm{C} / \mathrm{min}$ ramp, yielding the final perovskite material which was used in two step thermochemical $\mathrm{CO}_{2}$ splitting reactions.

A part of the powders obtained at $600^{\circ} \mathrm{C}$ was used for shaping cylindrical pellets (uniaxial pressing, $200 \mathrm{MPa}, 5 \mathrm{~min}, \varnothing=5 \mathrm{~mm}$ ) for sinterability investigations.

All sample references, corresponding formulations and synthesis methods are reported in Table 1.

Table 1: Powders formulations, synthesis methods and samples references.

\begin{tabular}{|c|c|c|}
\hline Formulation & Synthesis method & Sample reference \\
\hline \multirow{2}{*}{$\mathrm{La}_{0.5} \mathrm{Sr}_{0.5} \mathrm{MnO}_{3}$} & Pechini-1 & LSM-P1 \\
\hline & Pechini-2 & LSM-P2 \\
\hline \multirow{2}{*}{$\mathrm{La}_{0.5} \mathrm{Sr}_{0.5} \mathrm{Mn}_{0.6} \mathrm{Al}_{0.4} \mathrm{O}_{3}$} & Pechini-1 & LSMAl-P1 \\
\hline & Pechini-2 & LSMAl-P2 \\
\hline \multirow{2}{*}{$\mathrm{La}_{0.5} \mathrm{Sr}_{0.5} \mathrm{Mn}_{0.9} \mathrm{Mg}_{0.1} \mathrm{O}_{3}$} & Pechini-1 & LSMMg-P1 \\
\hline & Pechini-2 & LSMMg-P2 \\
\hline $\mathrm{La}_{0.5} \mathrm{Sr}_{0.5} \mathrm{Mn}_{0.8} \mathrm{Ga}_{0.2} \mathrm{O}_{3}$ & \multirow{7}{*}{ Pechini-2 } & LSMGa-P2 \\
\hline $\mathrm{La}_{0.5} \mathrm{Sr}_{0.5} \mathrm{Mn}_{0.6} \mathrm{Cr}_{0.4} \mathrm{O}_{3}$ & & LSMCr-P2 \\
\hline $\mathrm{La}_{0.5} \mathrm{Ca}_{0.5} \mathrm{MnO}_{3}$ & & LCM-P2 \\
\hline $\mathrm{La}_{0.5} \mathrm{Ca} 0.5 \mathrm{Mn}_{0.6} \mathrm{Al}_{0.4} \mathrm{O}_{3}$ & & LCMA1-P2 \\
\hline $\mathrm{La}_{0.5} \mathrm{Ca}_{0.5} \mathrm{Mn}_{0.9} \mathrm{Mg}_{0.1} \mathrm{O}_{3}$ & & LCMMg-P2 \\
\hline $\mathrm{La}_{0.5} \mathrm{Ca}_{0.5} \mathrm{Mn}_{0.8} \mathrm{Ga}_{0.2} \mathrm{O}_{3}$ & & LCMGa-P2 \\
\hline $\mathrm{La}_{0.5} \mathrm{Ca}_{0.5} \mathrm{Mn}_{0.6} \mathrm{Cr}_{0.4} \mathrm{O}_{3}$ & & LCMCr-P2 \\
\hline
\end{tabular}

\subsection{Characterization methods}

The main physico-chemical characteristics (morphology, chemical composition, crystalline structure, and microstructure) of the $\mathrm{P} 1$ and $\mathrm{P} 2$ powders prepared at either $600^{\circ} \mathrm{C}$ or $1400^{\circ} \mathrm{C}$ have been determined and compared. The powders morphology and grain sizes were observed by Field Emission Scanning Electron Microscopy (FESEM - Hitachi S4800). The composition homogeneity has been evaluated by Back Scattered Electrons analysis (FESEM- Zeiss EVO HD15) and elemental mapping was obtained by Energy Dispersive X-ray analysis (Aztec EDXOxford Instruments). Materials microstructure has been analyzed by $\mathrm{N}_{2}$ physisorption (Micromeritics ASAP-2000), after outgasing at $200{ }^{\circ} \mathrm{C}$ overnight. The BET method [30] was used to estimate the specific surface area $\left(\mathrm{S}_{\mathrm{BET}}\right)$ of the powders. X-ray diffraction $(\mathrm{XRD})$ patterns were 
recorded at room temperature on X'pert Pro (Panalytical) diffractometer equipped with $\mathrm{Cu} \mathrm{K} \alpha$ radiation $(\lambda=0.15418 \mathrm{~nm})$ at the tube current of $20 \mathrm{~mA}$, potential of $40 \mathrm{kV}$ and angle variation of $0.053052 \%$. High temperature X-ray diffractometer (HT XRD- Empyrean Panalytical with Anton-Paar HTK16 chamber) equipped with $\mathrm{Co} \mathrm{K} \alpha$ radiation $(\lambda=0.17903 \mathrm{~nm})$ was used for in situ investigation of phase transitions (tube current $30 \mathrm{~mA}$, potential $40 \mathrm{kV}$, angle variation $0.020516^{\circ} \mathrm{s}$, ramp temperature in the chamber $5{ }^{\circ} \mathrm{C} / \mathrm{min}$ ). A L74 optical dilatometer (Linseis) was used to analyze the sintering behavior of the powders (pressed in pellets) in air up to $1550^{\circ} \mathrm{C}$ with a temperature ramp of $15^{\circ} \mathrm{C} / \mathrm{min}$. The densities of pellets derived from $\mathrm{P} 1$ and $\mathrm{P} 2$ powder series have been measured before and after dilatometry experiments in terms of both density value and estimated percentage of theoretical density $\left(\% \mathrm{~d}_{\mathrm{th}}\right)$. For this latter, a density of $\sim 6.5$ $\mathrm{g} / \mathrm{cm}^{3}$ has been used for the fully dense LSM materials series.

The thermochemical $\mathrm{CO}_{2}$ splitting reactivity of the powders obtained at $1400^{\circ} \mathrm{C}$ was studied via thermogravimetric analysis (TGA - SETARAM SETSYS) using a platinum crucible. About 100 mg of powder were used for each TGA experiment. The temperature was first increased to 1400 ${ }^{\circ} \mathrm{C}\left(20{ }^{\circ} \mathrm{C} / \mathrm{min}\right)$ under argon $\left(99.999 \%\right.$ purity, $<2 \mathrm{ppm}$ of $\left.\mathrm{O}_{2}, 0.020 \mathrm{NL} / \mathrm{min}\right)$ to perform the thermal reduction. After $45 \mathrm{~min}$ dwell at $1400^{\circ} \mathrm{C}$, the temperature was decreased to $1050{ }^{\circ} \mathrm{C}(20$ $\left.{ }^{\circ} \mathrm{C} / \mathrm{min}\right)$. A mixture of $\mathrm{CO}_{2}$ and $\mathrm{Ar}(1: 1)$ was then introduced $(0.010 \mathrm{NL} / \mathrm{min}$ for each) in the system to perform the oxidation step, during $60 \mathrm{~min}$. Finally, the temperature was increased again to $1400{ }^{\circ} \mathrm{C}$ under $\mathrm{Ar}$, and the thermal reduction and $\mathrm{CO}_{2}$ splitting reaction cycle was operated again. The mass variation due to oxygen release during the thermal reduction step and oxygen uptake during $\mathrm{CO}_{2}$ splitting step was recorded continuously, and the amounts of $\mathrm{O}_{2}$ and $\mathrm{CO}$ produced were calculated. The $\mathrm{O}_{2}$ amount $\left(\mathrm{n}_{\mathrm{O} 2}\right)$ produced per gram of perovskite during the reduction step was calculated by the equation (3):

$$
n_{\mathrm{O}_{2}}=\frac{\Delta m_{\text {loss }}}{m \cdot M_{\mathrm{O}_{2}}}
$$


where $\Delta m_{\text {loss }}$ is the mass loss measured by TGA during the reduction step; $M_{\mathrm{O}_{2}}$ is the molecular weight of $\mathrm{O}_{2}$ and $m$ is the mass of perovskite powder in the crucible. The amount of $\mathrm{CO}\left(\mathrm{n}_{\mathrm{CO}}\right)$ produced per gram of perovskite during the oxidation step was calculated by the equation (4):

$$
n_{C O}=\frac{\Delta m_{\text {gain }}}{m \cdot M_{\mathrm{O}}}
$$

where $\Delta m_{\text {gain }}$ is the mass gain during the re-oxidation step and $M_{\mathrm{O}}$ is the molecular weight of oxygen. Two successive redox cycles were performed for each sample with the same reaction conditions as above.

The re-oxidation yield was also calculated to evidence whether the oxidation step was complete or not. It was defined as the amount of oxygen recovered by the material vs. the amount of oxygen lost during the just-prior reduction and was calculated according the equation (5):

$$
\text { Re }- \text { oxidation yield }=\frac{n_{C O}}{2 \cdot n_{\mathrm{O}_{2}}}
$$

\section{Results and discussion}

As already stressed in the introduction, the optimization of perovskite oxides formulation, structure and microstructure, cannot be dissociated from an investigation of their ability to be easily shaped and sintered. This is strongly required to ensure their efficient integration in thermochemical splitting reactors. In order to reach this goal, the sinterability of LSM, LSMMg and LSMAl powder series prepared by P1 and P2 Pechini-derived protocols has been first investigated before further analysis of their characteristics and redox properties. The LSM, LSMMg and LSMAl formulations were selected from the literature data because of their promising properties in terms of $\mathrm{O}_{2}$ and $\mathrm{CO}$ production while providing high re-oxidation yield $[13,31,32]$. The strong differences evidenced when comparing the sintering behavior of the P1 and P2 powder series have been discussed on the basis of their structural and microstructural characteristics. Afterwards, the redox activity of the powders materials for the $\mathrm{CO}_{2}$ splitting 
reaction has been also evidenced. Finally, the insertion of other dopants ( $\mathrm{Ca}$ on $\mathrm{A}$ site and $\mathrm{Ga}$ or $\mathrm{Cr}$ on $\mathrm{B}$ site) has been considered in order to further refine the formulation of the most attractive P2 powders, yielding enhanced reduction and oxidation extents during the $\mathrm{CO}_{2}$ splitting redox cycle.

\subsection{Powders sinterability}

The sinterability of the $\mathrm{P} 1$ and $\mathrm{P} 2$ powder series prepared at $600^{\circ} \mathrm{C}$ has been investigated by optical dilatometry from room temperature up to $1550{ }^{\circ} \mathrm{C}$ using pressed pellets (green density in the range $30-35 \% \mathrm{~d}_{\mathrm{th}}$ ). Dilatometric measurements were carried out to highlight the possibility of tuning the powders sintering behavior for further shaping studies and optimizations (e.g. dense membranes, or consolidated porous materials, or asymmetric membranes with a stacking of dense and porous layers to facilitate access/release of gases...). Although the upper limit for the dilatometer is $1600^{\circ} \mathrm{C}$, the studied temperature was high enough when considering that the thermochemical cycling reaction does not overpass $1400^{\circ} \mathrm{C}$. The dilatometric curves of LSM, LSMMg and LSMAl samples are compared in Figure 1.

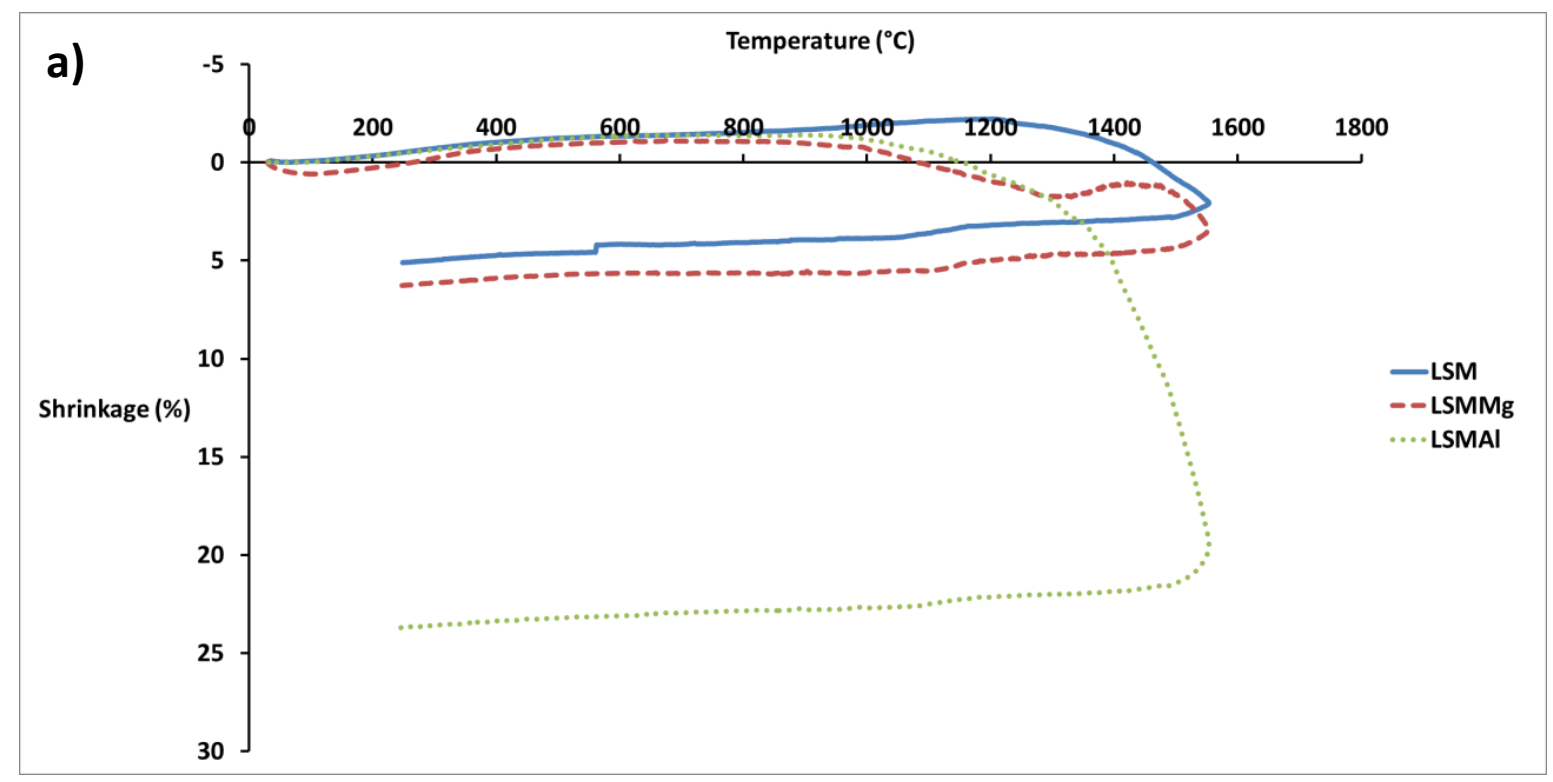




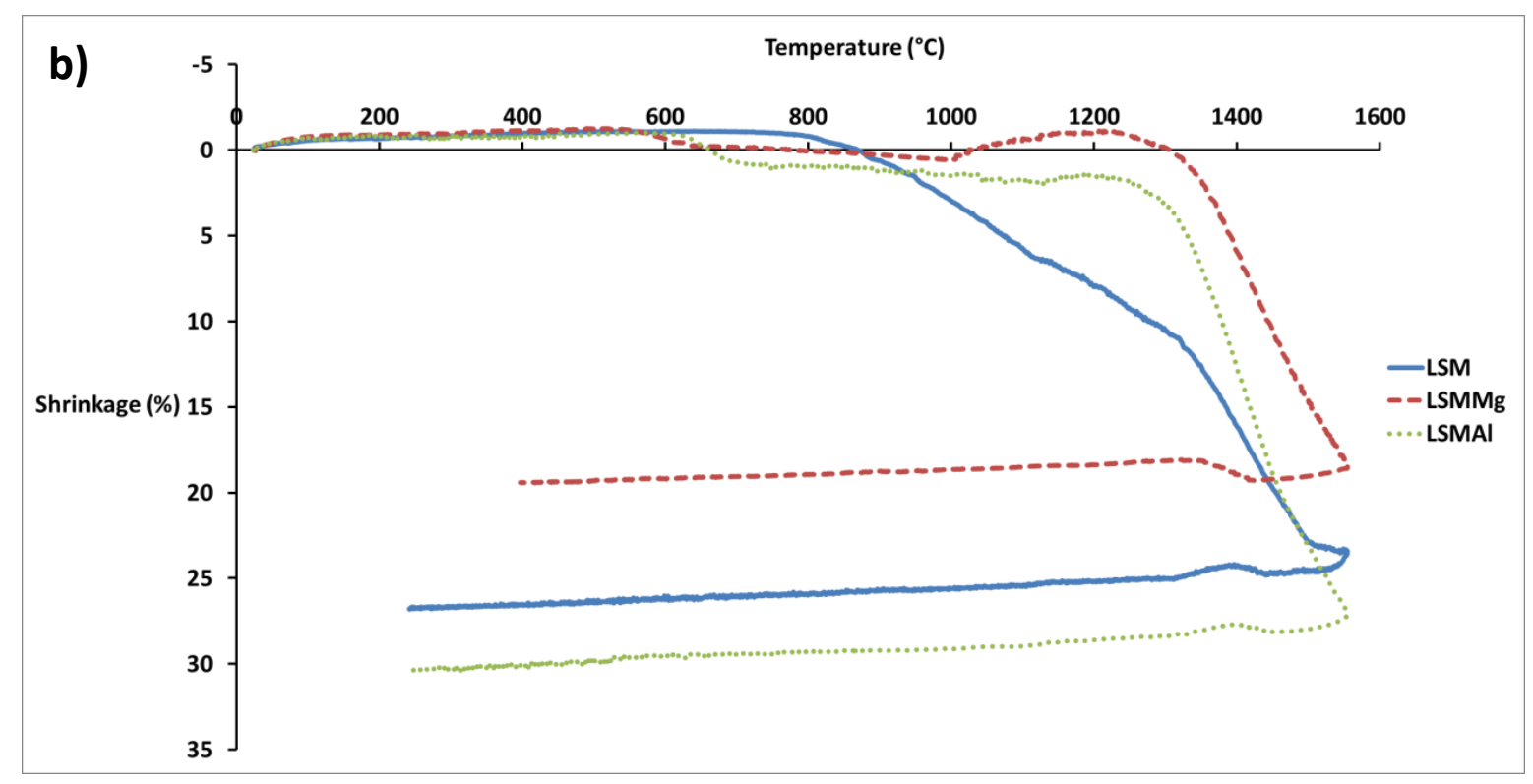

Figure 1: Dilatometric curves of LSM-based pellets derived from (a) P1- and (b) P2-powders obtained at $600^{\circ} \mathrm{C}$. Influence of $\mathrm{Al}$ and $\mathrm{Mg}$ dopants. The green density was in the range 30-35 $\% d_{t h}$.

All samples were found to exhibit the same behavior until $600{ }^{\circ} \mathrm{C}$, i.e. the powders synthesis temperature. The negative shrinkage values for both LSM-P1 and LSM-P2 correspond to the thermal expansion in the low-middle temperature range before sintering. In the P1-powder series (Figure 1.a.), the shrinkage of undoped LSM-P1 starts only around $1200{ }^{\circ} \mathrm{C}$ whereas it begins already at $900{ }^{\circ} \mathrm{C}$ for LSMAl-P1 and LSMMg-P1. Very low shrinkage $(\sim 1 \%)$ is observed at $1400^{\circ} \mathrm{C}$ for undoped LSM-P1 and it reaches $4 \%$ at $1550{ }^{\circ} \mathrm{C}$ (final density $=2.7 \mathrm{~g} / \mathrm{cm}^{3}$, i.e. $\sim 42$ $\left.\% \mathrm{~d}_{\mathrm{th}}\right)$. Both LSMAl-P1 and LSMMg-P1 exhibit the same sintering behavior until $1300^{\circ} \mathrm{C}$. Above this temperature, the shrinkage of the Al-doped sample is much more pronounced. At $1400{ }^{\circ} \mathrm{C}$, the effective shrinkage of LSMAl-P1 is $\sim 6 \%$ and reaches $\sim 20 \%$ at $1550{ }^{\circ} \mathrm{C}$ (final density $=3.2$ $\mathrm{g} / \mathrm{cm}^{3}$, i.e. $\left.\sim 49 \% \mathrm{~d}_{\mathrm{th}}\right)$. Regarding LSMMg-P1, the shrinkage starts at $900{ }^{\circ} \mathrm{C}$ but interrupts between $1300{ }^{\circ} \mathrm{C}$ and $1400{ }^{\circ} \mathrm{C}$, probably due to a phase transition. The effective shrinkage of LSMMg-P1 is $\sim 2 \%$ at $1400{ }^{\circ} \mathrm{C}$ and $\sim 4 \%$ at $1550{ }^{\circ} \mathrm{C}$ (final density $=2.8 \mathrm{~g} / \mathrm{cm}^{3}$, i.e. $\sim 43 \% \mathrm{~d}_{\mathrm{th}}$ ).

In the P2-powder series (Figure 1.b.), the shrinkage of undoped LSM-P2 begins at $\sim 800{ }^{\circ} \mathrm{C}$ whereas it starts only at $\sim 1200{ }^{\circ} \mathrm{C}$ for LSMAl-P2 and LSMMg-P2. A stabilization of the 
shrinkage is observed above $1500{ }^{\circ} \mathrm{C}$ for undoped LSM, whereas LSMAl and LSMMg are not stabilized even at $1550{ }^{\circ} \mathrm{C}$. A significant difference in the shrinkage rate is observed at $1400{ }^{\circ} \mathrm{C}$ and the highest value is for LSM-P2 $(\sim 17 \%)$. A phase transition can be suspected for all samples: in the range $1100-1300{ }^{\circ} \mathrm{C}$ for LSM-P2 and $1100-1200{ }^{\circ} \mathrm{C}$ for LSMAl-P2. Above $1200{ }^{\circ} \mathrm{C}$, a fast sintering is observed for LSMAl-P2, with an effective shrinkage reaching $\sim 15 \%$ at $1400{ }^{\circ} \mathrm{C}$ and above $27 \%$ at $1550{ }^{\circ} \mathrm{C}$. Comparable shrinkage values are measured at $1400{ }^{\circ} \mathrm{C}$ for LSM-P2 and LSMAl-P2, but higher sinterability is observed for LSMAl-P2, as its sintering starts $\sim 400{ }^{\circ} \mathrm{C}$ later. Final densities after the thermal treatment at $1550{ }^{\circ} \mathrm{C}$ for LSM-P2 and LSMAl-P2 are respectively $5.5 \mathrm{~g} / \mathrm{cm}^{3}\left(\sim 85 \% \mathrm{~d}_{\mathrm{th}}\right)$ and $5.1 \mathrm{~g} / \mathrm{cm}^{3}\left(\sim 78 \% \mathrm{~d}_{\mathrm{th}}\right)$.

$\mathrm{Mg}$ revealed to be an efficient dopant for increasing the thermal stability of LSM powders. This is evidenced by the low sinterability of LSMMg-P2: $\sim 5 \%$ shrinkage at $1400{ }^{\circ} \mathrm{C}$ and below $18 \%$ at $1550{ }^{\circ} \mathrm{C}$ (final density $=3.9 \mathrm{~g} / \mathrm{cm}^{3}$, i.e. $\sim 60 \% \mathrm{~d}_{\mathrm{th}}$ ). For LSMMg-P2, a phase transition is suspected between $1000{ }^{\circ} \mathrm{C}$ and $1200{ }^{\circ} \mathrm{C}$.

For all powder formulations, a phase transition is also suspected to take place during the cooling step: in the range $1400^{\circ} \mathrm{C}-1300^{\circ} \mathrm{C}$ for $\mathrm{P} 2$ samples and $1200-1100^{\circ} \mathrm{C}$ for $\mathrm{P} 1$ samples. In order to confirm this hypothesis, high temperature XRD analyses of LSM-P1 and LSM-P2 powders were carried out (see next section).

The dilatometry results clearly evidence that the P1-powders offer very low sinterability and poor densification below $1400{ }^{\circ} \mathrm{C}$ whereas the P2-powders feature enhanced sintering. According to the literature, the P1 method is classically used to prepare both ceria and perovskite powders $[21,33,34]$ without any further shaping process (e.g. for application in fluidized beds catalytic reactors or thermogravimetric analysis). The P2 method, using higher quantity of organics, is more comparable to the original Pechini process [29,35] and its application allowed obtaining easily defect-free pellets by compaction and sintering of the corresponding P2-powders. Contrary, the formation and consolidation of pellets derived from P1-powders was almost impossible 
(delamination, desegregation) when using conventional uniaxial pressing and sintering conditions. Hence, powders with low sinterability (P1) could be used directly as loose powders or aggregates, whereas the highly sinterable powders (P2) are rather recommended for designing dense membranes. A partial (controlled) sintering of P2 powders could also be explored to consolidate porous layers with good adhesion on inorganic supports. In addition, monoliths could be obtained after introducing additional interconnected micrometric pores (porogens) to favor gas access to the material bulk, and thus increase redox activity.

\subsection{Structural and microstructural characterization of perovskite powders}

In order to explain the strong differences in the sintering behavior of P1- and P2-powders, their microstructure, morphology and crystalline structure have been compared.

\subsubsection{Crystalline structure}

The diffraction patterns of P1-powder series reveal a multiphasic structure (Figure 2) which could drastically impact the sintering process. At $600{ }^{\circ} \mathrm{C}$, additional diffraction peaks are detected in the XRD pattern expected for a LSM perovskite phase. The peaks at $2 \theta=25^{\circ}$ and $2 \theta=36^{\circ}$ reveal the presence of strontium carbonate $\mathrm{SrCO}_{3}$ (orthorhombic, ICDD 00-005-0418) (Figure 2.a) while the peaks at $2 \theta=31^{\circ}$ and $2 \theta=44^{\circ}$ are representative of $\mathrm{Sr}_{1.5} \mathrm{La}_{0.5} \mathrm{MnO}_{4}$ (tetragonal, ICDD 04-0135773). This finding can be related to the high strontium content in the samples that enhances the activity of SrO and increases the Gibbs free-energy of the LSM perovskites resulting in the formation of undesirable secondary phases [36]. Comparative analyses of the powders prepared at different temperatures in the range $600^{\circ} \mathrm{C}-1400^{\circ} \mathrm{C}\left(5^{\circ} \mathrm{C} / \mathrm{min}, 1 \mathrm{~h}\right)$ evidenced that the additional peaks totally disappear between $1200{ }^{\circ} \mathrm{C}$ and $1400{ }^{\circ} \mathrm{C}$. It is also important to note that the diffraction peaks at $1400^{\circ} \mathrm{C}$ are not perfectly well defined, with either a non-symmetrical shape or a double diffraction peak as observed at $2 \theta=32-33^{\circ}$. This double peak is associated with LSM rhombohedral phase (ICDD 04-012-7739), remaining at high temperature. The LSM structure is 
reported as rhombohedral up to a Sr substitution of $30-40 \%$ on the A-site and it becomes cubic above this value $[37,38]$. Coexistence of the two phases (cubic and rhombohedral) is evidenced in Figure 2.b ; a decrease of the first peak intensity $\left(2 \theta=32.3^{\circ}\right)$ to the benefit of the second one $(2 \theta$ $=32.8^{\circ}$ ) reveals a transition from rhombohedral to cubic phase (ICDD 04-007-0052) with rising temperature. However, the structure was still not purely cubic at $1400^{\circ} \mathrm{C}$ as the diffraction peak remains large with a shoulder. There is no doubt that such a structural evolution in the samples during the thermal treatment should strongly impact on the sintering process.

The XRD patterns of the LSM-P1 powder after two thermochemical cycles (TCC) with $\mathrm{CO}_{2}$ in the TGA, reveal well defined narrow and intense peaks, characteristic of a well crystallized perovskite. Thermochemical cycling thus allows completing the formation of the cubic perovskite phase which was not perfectly formed after the initial $1 \mathrm{~h}$ thermal treatment at $1400^{\circ} \mathrm{C}$.

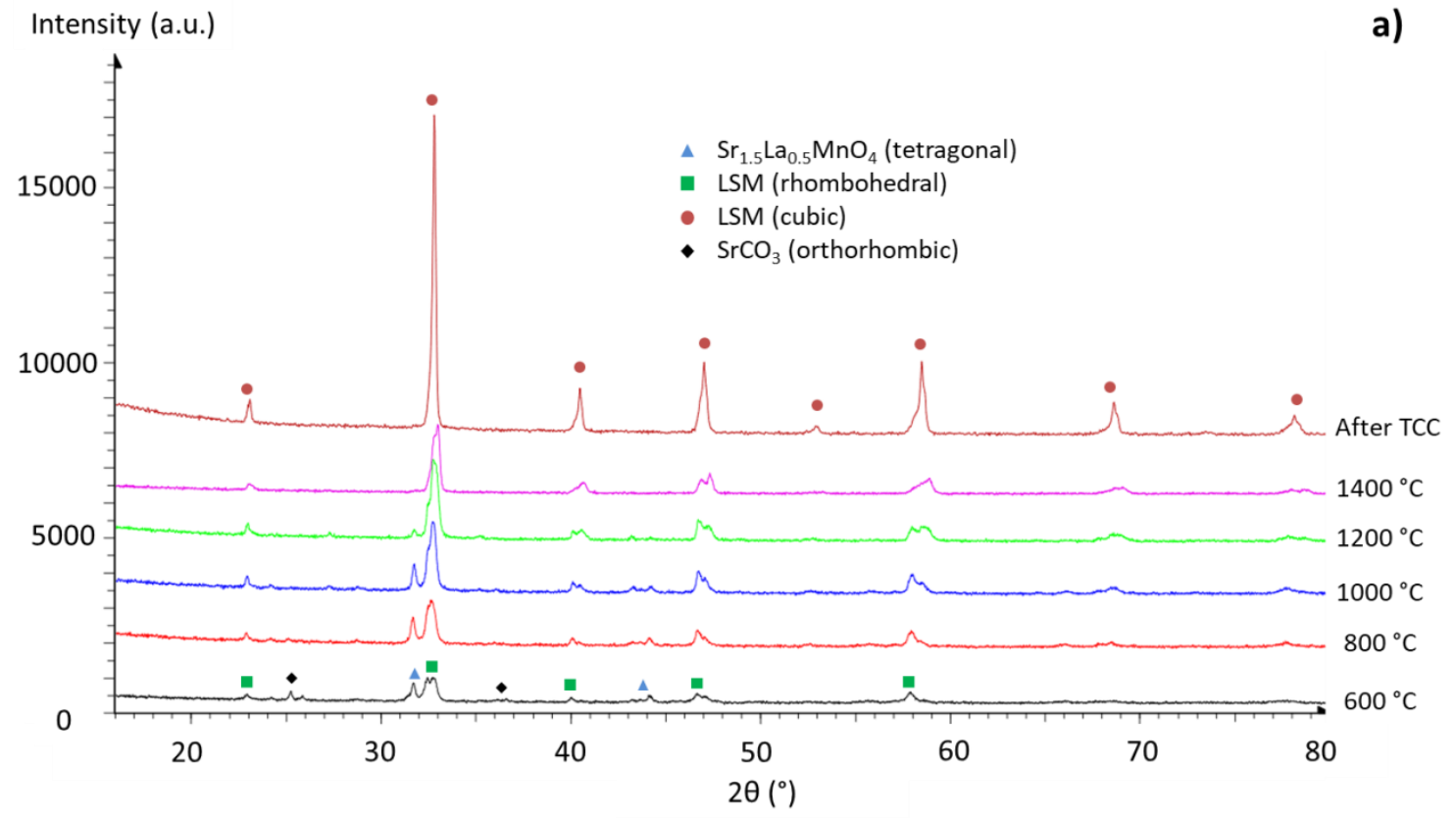




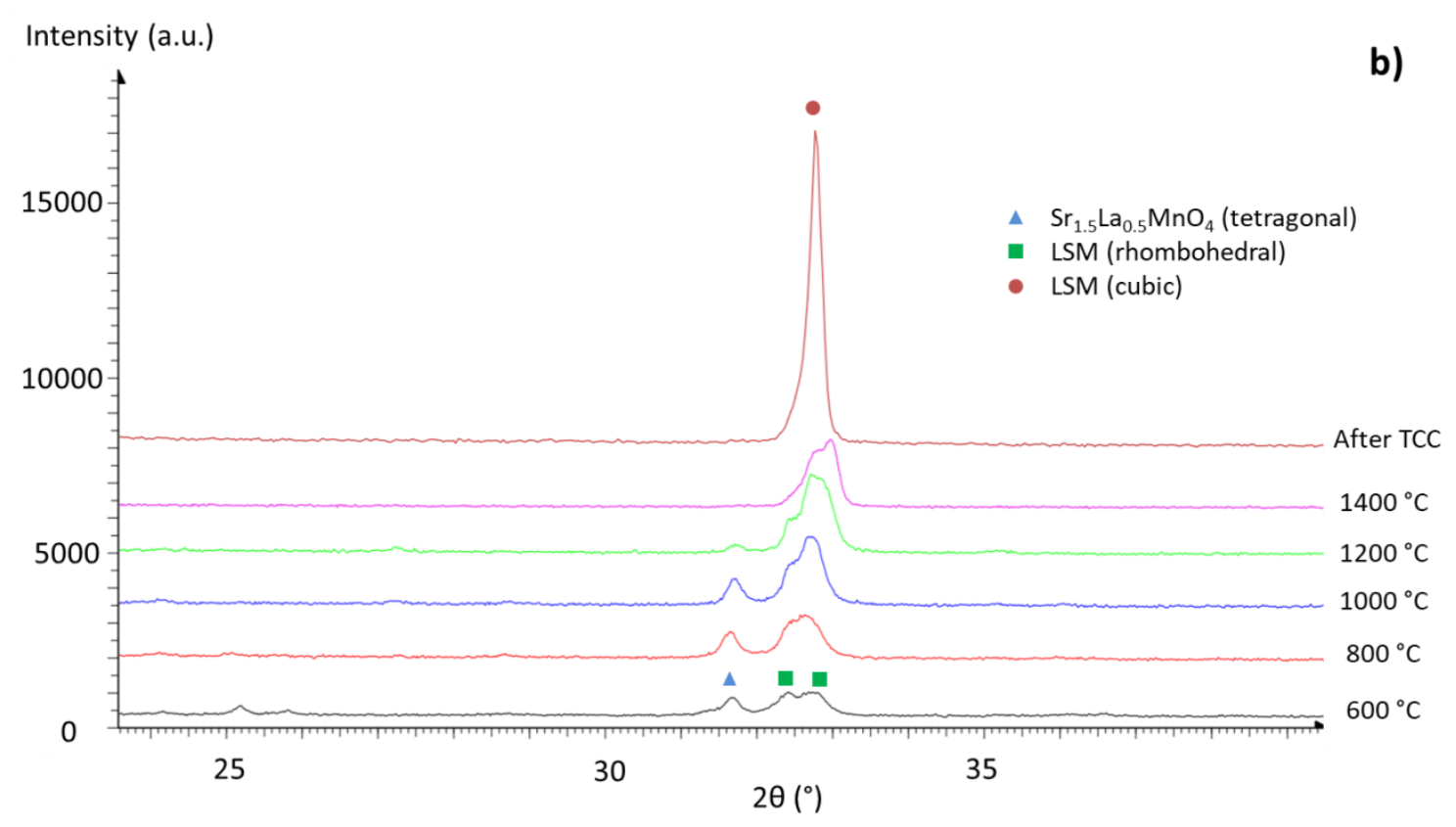

Figure 2: Room temperature XRD patterns of LSM-P1 powders obtained at different temperatures and after two thermochemical cycles with $\mathrm{Ar} / \mathrm{CO}_{2}$ (TCC).

a) Whole pattern in the range $\left.2 \theta=16-80^{\circ}, b\right)$ Zoom in the range $2 \theta=23-40^{\circ}$.

HT XRD analysis of LSM-P1 powder confirmed the results obtained during room temperature (RT) XRD analysis. Noticeably, the reversible peak shift toward small angles due to temperature rise reveals a unit cell dilatation. The $\mathrm{Sr}_{1.5} \mathrm{La}_{0.5} \mathrm{MnO}_{4}, \mathrm{SrCO}_{3}$ and $\mathrm{LSM}$ rhombohedral phases are present at $600{ }^{\circ} \mathrm{C}$. At $1000{ }^{\circ} \mathrm{C}$, some $\mathrm{SrO}$ (cubic, Fm3m, ICDD 00-048-1477) does form as proven by the peaks at $2 \theta=34.5^{\circ}$ and $40.5^{\circ}$, and then disappears above $1200{ }^{\circ} \mathrm{C}$. At $1300{ }^{\circ} \mathrm{C}$, a $\mathrm{Mn}_{3} \mathrm{O}_{4}$ (tetragonal, $\mathrm{I}_{1} / \mathrm{amd}$, ICDD 00-024-0734) does form and disappears as $\mathrm{SrMnO}_{3}$ (hexagonal, P63/mmc, ICDD 00-024-1213) was observed at $1500^{\circ} \mathrm{C}\left(2 \theta=31.8^{\circ}\right.$ and $\left.2 \theta=41.3^{\circ}\right)$. $\mathrm{SrMnO}_{3}$ remains in the sample even after returning to room temperature. It is important to note that additional peaks corresponding to the Pt-Rh holder $\left(2 \theta=46.8^{\circ}\right.$ and $\left.50.5^{\circ}\right)$ appear during the analysis above $1300{ }^{\circ} \mathrm{C}$. This is due to both the improvement of $\mathrm{Pt}-\mathrm{Rh}$ holder crystallinity at high temperature and the very low thickness of the powder sample. 


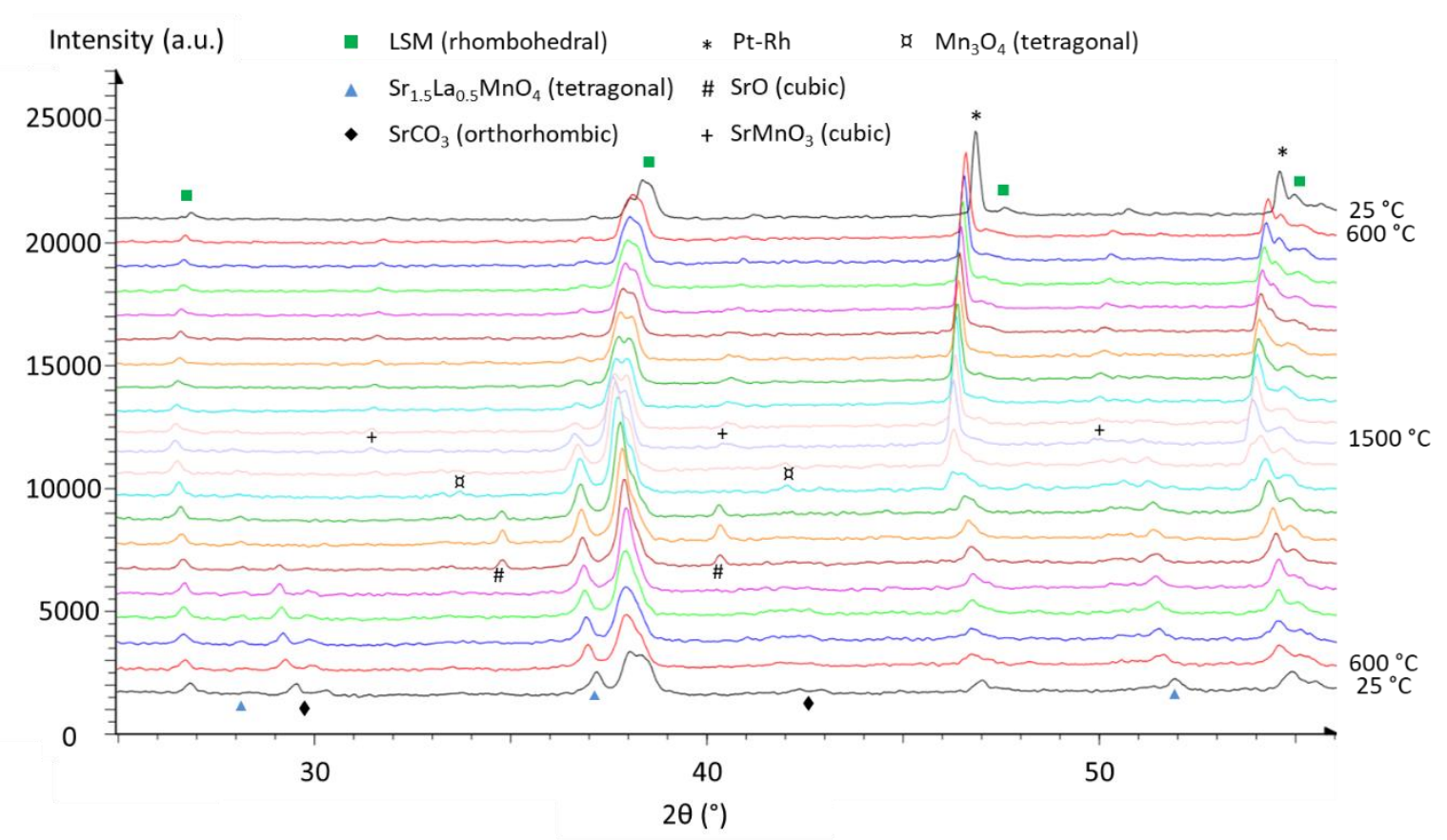

Figure 3: High temperature XRD patterns $\left(2 \theta=25-56^{\circ}\right)$ of LSM-P1 powder, Co Ka radiation $(\lambda=0.17903 \mathrm{~nm})$ from $600^{\circ} \mathrm{C}$ to $1500^{\circ} \mathrm{C}$ with a $100^{\circ} \mathrm{C} \mathrm{step} \mathrm{(lower} \mathrm{part)} \mathrm{and} \mathrm{cooling} \mathrm{back} \mathrm{to} 600$ ${ }^{\circ} \mathrm{C}$ (upper part). XRD patterns at $25^{\circ} \mathrm{C}$ before (lower part) and after heating (upper part) are shown for comparison.

The LSM rhombohedral structure persists even after the long thermal treatment thus confirming that $\mathrm{CO}_{2}$ splitting cycle has a beneficial effect for the formation of cubic LSM. During HTXRD analysis, cubic LSM forms at $900{ }^{\circ} \mathrm{C}$ but comes back to a rhombohedral structure when $\mathrm{SrO}$ and $\mathrm{Mn}_{3} \mathrm{O}_{4}$ start to form.

The XRD patterns of the $\mathrm{P} 2$ powder obtained at $1400^{\circ} \mathrm{C}$ (Figure 4) reveal a single perovskite phase. This phase with mainly a cubic structure $(\mathrm{Pm} 3 \mathrm{~m})$ is already formed at $600{ }^{\circ} \mathrm{C}$ and remains unchanged until $1400{ }^{\circ} \mathrm{C}$. Consistently, it is stated in the literature that the increase of both CA and EG content in the Pechini process is recommended to get the perovskite material formed at lower temperature [39]. The highest intensity and refinement of the diffraction peaks observed at $1400^{\circ} \mathrm{C}$ result from continuous crystallite growth. Compared to LSM-P1, the presence of $\mathrm{SrCO}_{3}$ and $\mathrm{Sr}_{1.5} \mathrm{La}_{0.5} \mathrm{MnO}_{4}$ is limited in LSM-P2.

The XRD patterns of LSM-P2 after two thermochemical cycles (TCC) in TGA reveals well defined narrow and intense peaks which are characteristic of a cubic perovskite phase. The same 
result was obtained for LSM-P1, thus demonstrating that the synthesis protocol has no influence on the crystalline structure of the final material obtained after thermochemical cycling with $\mathrm{Ar} / \mathrm{CO}_{2}$, although it strongly affects the starting powders sinterability.
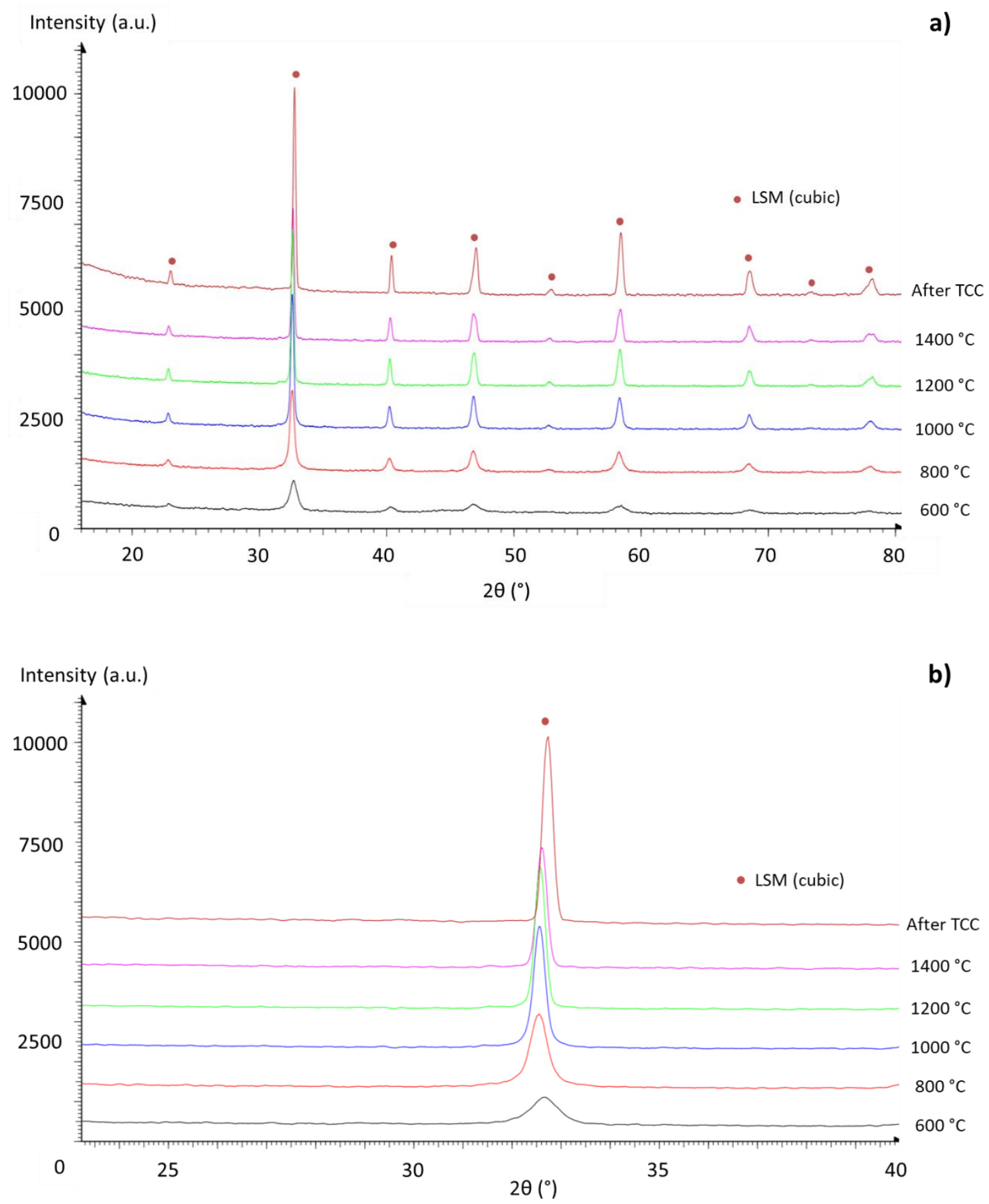

Figure 4: Room temperature XRD patterns of LSM-P2 powders obtained at different temperatures and after two thermochemical cycles with $\mathrm{Ar} / \mathrm{CO}_{2}$ (TCC).

a) Whole pattern in the range $\left.2 \theta=16-80^{\circ}, b\right)$ Zoom in the range $2 \theta=23-40^{\circ}$. 
HT XRD analysis of LSM-P2 powder (Figure 5) confirms the results obtained by RT XRD analysis: both $\mathrm{Sr}_{1.5} \mathrm{La} 0.5 \mathrm{MnO}_{4}$ and $\mathrm{SrCO}_{3}$ are present in small quantities and LSM cubic phase is already formed at $600{ }^{\circ} \mathrm{C}$. SrO appears at low temperature $\left(900-1000{ }^{\circ} \mathrm{C}\right)$ while $\mathrm{Mn}_{3} \mathrm{O}_{4}$ formation is hardly detected and may be hidden in the base line. Between $1100{ }^{\circ} \mathrm{C}$ and $1300{ }^{\circ} \mathrm{C}$, the minor $\mathrm{SrMnO}_{3}$ phase forms and disappears during sample cooling (contrary to LSM-P1 sample in which $\mathrm{SrMnO}_{3}$ phase persists during cooling). This phase formation at high temperature observed by XRD could be responsible for the delays observed on dilatometric curves during heating between 1100 and $1300{ }^{\circ} \mathrm{C}$. However, XRD analysis hardly correlates with the dilatometric behavior during the cooling step (i.e. dimensional variation vs. XRD phase evolution is not straightforward).

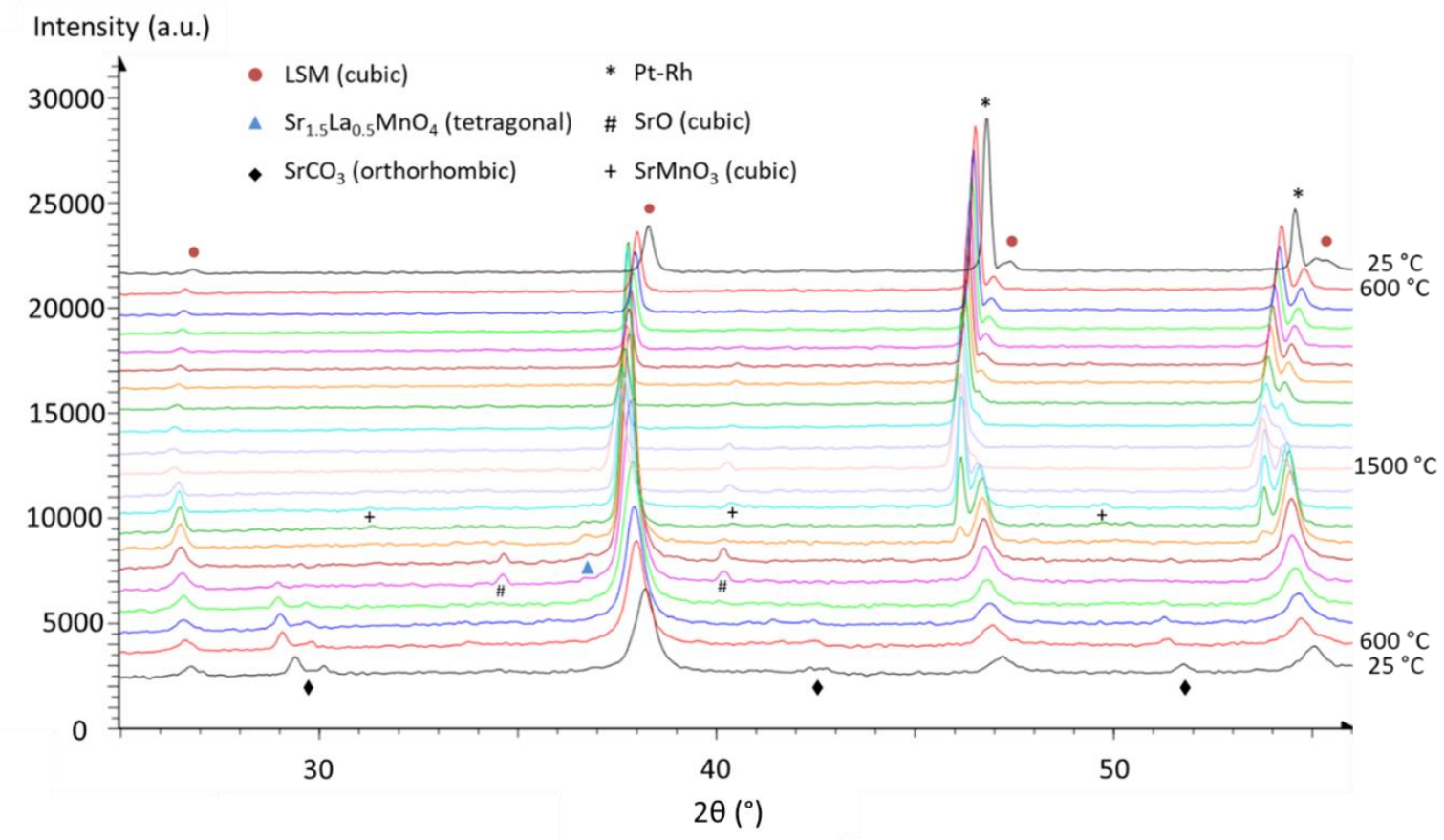

Figure 5: High temperature XRD patterns $\left(2 \theta=25-56^{\circ}\right)$ of LSM-P2 powder, Co Ka radiation $(\lambda=0.17903 \mathrm{~nm})$ from $600^{\circ} \mathrm{C}$ to $1500^{\circ} \mathrm{C}$ with a $100^{\circ} \mathrm{C}$ step (lower part) and cooling back to 600 ${ }^{\circ} \mathrm{C}$ (upper part). XRD patterns at $25^{\circ} \mathrm{C}$ before (lower part) and after heating (upper part) are shown for comparison. 


\subsubsection{Morphology and microstructure}

The sinterability of the LSM-based powder series has been first correlated with the evolution of their specific surface areas $\left(\mathrm{S}_{\mathrm{BET}}\right)$. The $\mathrm{S}_{\mathrm{BET}}$ values for LSM, LSMAl and LSMMg powders obtained by $\mathrm{P} 1$ and $\mathrm{P} 2$ methods at $600{ }^{\circ} \mathrm{C}$ and $1400{ }^{\circ} \mathrm{C}$, are compared in Table 2 . The low $\mathrm{S}_{\mathrm{BET}}$ values of P1 powders reveal no significant difference between the values obtained for powders prepared at $600{ }^{\circ} \mathrm{C}$ and $1400{ }^{\circ} \mathrm{C}$. This result is in line with the dilatometric analysis (low powder sintering). Mg-doped powders feature slightly higher S $_{\text {BET }}$ values than undoped LSM, although the Al-doped powders exhibit the highest $\mathrm{S}_{\mathrm{BET}}$ values $\left(13.9 \mathrm{~m}^{2} / \mathrm{g}\right)$ after the treatment at $1400^{\circ} \mathrm{C}$.

Table 2: Specific surface area of LSM-based powders obtained at $600^{\circ} \mathrm{C}$ and $1400^{\circ} \mathrm{C}$ by $P 1$ and $P 2$ methods. Influence of Al and $M g$ dopants.

\begin{tabular}{|c|c|c|c|c|c|c|}
\hline \multirow{2}{*}{ Synthesis temperature } & \multicolumn{6}{|c|}{ S $_{\text {BET }}\left(\mathrm{m}^{2} / \mathrm{g}\right)$} \\
\cline { 2 - 7 } & \multicolumn{2}{|c|}{ LSM } & \multicolumn{2}{c|}{ LSMA1 } & \multicolumn{2}{c|}{ LSMMg } \\
\cline { 2 - 7 } & $\mathrm{P} 1$ & $\mathrm{P} 2$ & $\mathrm{P} 1$ & $\mathrm{P} 2$ & $\mathrm{P} 1$ & $\mathrm{P} 2$ \\
\hline $600^{\circ} \mathrm{C}$ & 3.2 & 33.7 & 11.6 & 19.8 & 5.9 & 31.3 \\
\hline $1400^{\circ} \mathrm{C}$ & 2.8 & 4.3 & 13.9 & 1.3 & 3.6 & 1.7 \\
\hline
\end{tabular}

The $\mathrm{S}_{\mathrm{BET}}$ values measured at $600{ }^{\circ} \mathrm{C}$ for $\mathrm{P} 2$ powders were always higher than those measured for P1 powders. The S $_{\mathrm{BET}}$ values for LSM-P2 and LSMMg-P2 are up to ten times higher than those of their P1 counterparts. On the other hand $\mathrm{S}_{\mathrm{BET}}$ value for LSMAl-P2 is twice higher than that of LSMAl-P1. At $1400{ }^{\circ} \mathrm{C}$, the $\mathrm{S}_{\mathrm{BET}}$ values sharply decrease for all P2 powders and the highest value $\left(4.3 \mathrm{~m}^{2} / \mathrm{g}\right)$ was obtained for LSM-P2. Such strong decrease of $\mathrm{S}_{\mathrm{BET}}$ correlates with the high sintering of $\mathrm{P} 2$ powders in the corresponding temperature range. This result is also in line with the strong grain growth observed by FESEM for LSM-P2, as discussed below.

As known from the literature, the classically used P1 method involves an exothermic very fast and self-sustaining chemical reaction between the metal salts and the organic fuel, which is ignited at a temperature around $200^{\circ} \mathrm{C}$ (Figure S1). This exothermic behavior is recognized to be responsible for heterogeneities in the derived ceramic powders [28]. In the present work, localized 
ignition and nitrate decomposition to $\mathrm{NO}_{2}$ and $\mathrm{O}_{2}$ yielded LSM-based powders featuring a spongy microstructure (Figure 6.a) with different grain sizes as measured by FESEM (Table 3). Such a powder morphology is typically obtained by combustion reactions [40]. The FESEM images of LSMAl-P1 and LSMMg-P1 powders obtained at $600^{\circ} \mathrm{C}$ and $1400^{\circ} \mathrm{C}$ are shown in Figure S2.
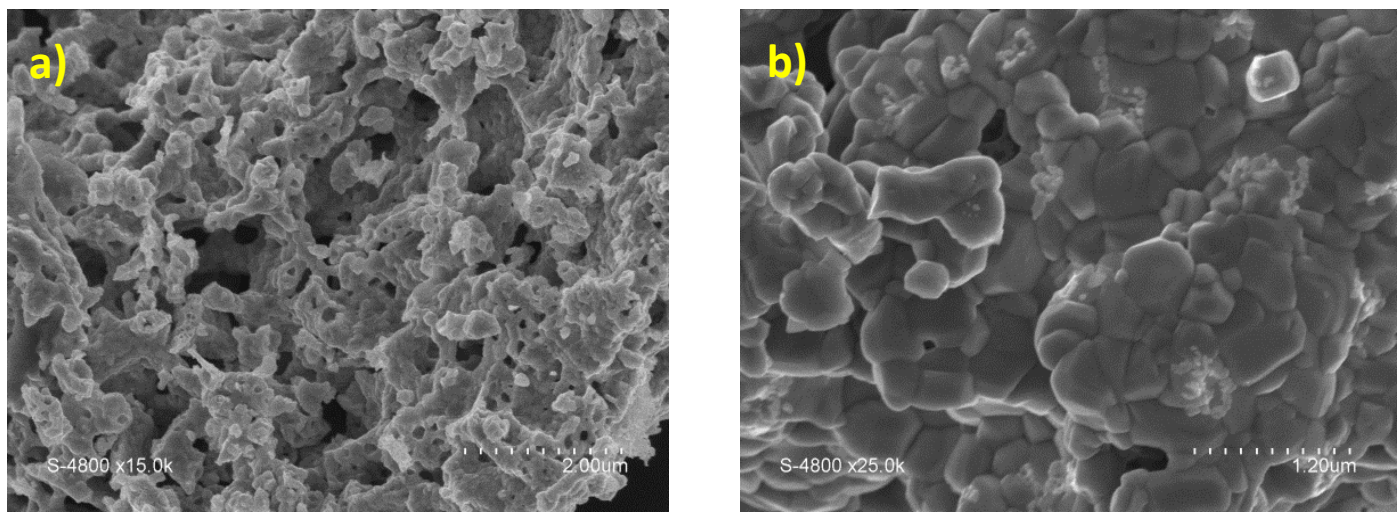

Figure 6: FESEM images of LSM-P1 powders obtained at $600^{\circ} \mathrm{C}($ a $)$ and $1400^{\circ} \mathrm{C}(\mathrm{b})$.

Table 3: Grain sizes measured by FESEM for LSM-based powders obtained at $600^{\circ} \mathrm{C}$ and $1400^{\circ} \mathrm{C}$. Influence of $\mathrm{Al}$ and $\mathrm{Mg}$ dopants.

\begin{tabular}{|c|c|c|c|c|c|c|}
\hline \multirow{2}{*}{ Synthesis temperature } & \multicolumn{5}{|c|}{ Grain sizes measured by FESEM (nm) } \\
\cline { 2 - 7 } & \multicolumn{2}{|c|}{ LSM } & \multicolumn{2}{c|}{ LSMAl } & \multicolumn{2}{c|}{ LSMMg } \\
\cline { 2 - 7 } & $\mathrm{P} 1$ & $\mathrm{P} 2$ & $\mathrm{P} 1$ & $\mathrm{P} 2$ & $\mathrm{P} 1$ & $\mathrm{P} 2$ \\
\hline $600{ }^{\circ} \mathrm{C}$ & $50-100$ & $20-30$ & $20-300$ & $30-60$ & $50-200$ & $10-20$ \\
\hline $1400{ }^{\circ} \mathrm{C}$ & $300-700$ & $600-1000$ & $200-800$ & $300-600$ & $200-500$ & $100-500$ \\
\hline
\end{tabular}

Grain size measurements (Table 3) reveal large size distributions for $\mathrm{P} 1$ powders at $600{ }^{\circ} \mathrm{C}$. Aldoped P1-powders show the largest size distribution at $600{ }^{\circ} \mathrm{C}$ although smaller grains were detected for both LSMMg-P1 and LSM-P1 (Figure 6.a.). At $1400{ }^{\circ} \mathrm{C}$ (Figure 6.b.), mean grain sizes are 7 times (LSM-P1) and 3 times (LSMAl-P1 and LSMMg-P1) bigger, respectively than those obtained at $600{ }^{\circ} \mathrm{C}$. These results confirm the original effect of $\mathrm{Al}$ and $\mathrm{Mg}$ doping for limiting LSM-perovskites grain growth at low-middle temperature (below $1000-1100{ }^{\circ} \mathrm{C}$ ) while activating uniform LSM sintering at higher temperature.

When using higher organic concentrations (P2 method, more comparable to the original Pechini process), a better complexation of the metallic cations is favored in the starting sol. The organic 
polyester matrix is expected to maintain a more uniform distribution of the metal cations and thus limit their reactivity (matrix dispersing effect). Accordingly, uniform microstructures were observed by FESEM for all P2 LSM-based powders. For undoped LSM-P2, small grain sizes in the range $20-30 \mathrm{~nm}$ were observed at $600{ }^{\circ} \mathrm{C}$ (Figure 7.a) while large aggregated/sintered micronsized grains were observed at $1400^{\circ} \mathrm{C}$ (Figure 7.b). The FESEM images of LSMAl-P2 and LSMMg-P2 obtained at $600^{\circ} \mathrm{C}$ and $1400^{\circ} \mathrm{C}$ are shown in Figure S3. The smallest grains (10-20 nm) were observed for Mg-doped sample.
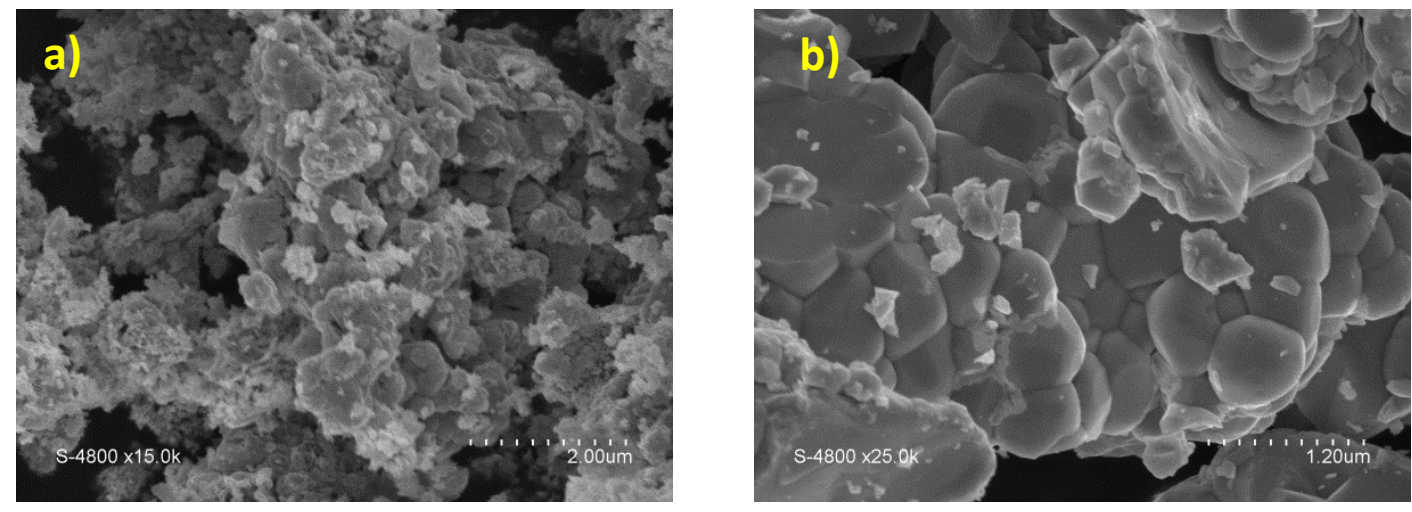

Figure 7: FESEM images of LSM-P2 powders obtained at $600^{\circ} \mathrm{C}(a)$ and $1400^{\circ} \mathrm{C}(\mathrm{b})$.

The extent of powders sintering vs. temperature has been first evaluated by comparing the evolution of particle sizes measured by FESEM. It was found that at $1400{ }^{\circ} \mathrm{C}$, grain growth strongly depends on the dopant. At $1400{ }^{\circ} \mathrm{C}$, grain sizes are respectively $\sim 30$ times (LSM-P2), $\sim 10$ times (LSMAl-P2), and 20 times (LSMMg-P2) larger than those measured at $600{ }^{\circ} \mathrm{C}$. Such strong grain growth and sintering phenomena observed by FESEM for the P2-powders was not evidenced for the P1-powder series. Again, $\mathrm{Al}$ and $\mathrm{Mg}$ doping effects were easily identified by the higher microstructural stability of powders at high temperature. The final grain sizes of undoped LSM-P2 were 2.5 times larger than those of LSMMg-P2 with only $10 \%$ B-site-substitution.

For the LSMAl-P1 powder, two types of grains were revealed by the significant contrast observed on High Definition Back Scattered Detector (HDBSD) images. Dark grains were found to be rich in both $\mathrm{Sr}$ and $\mathrm{Al}$ whereas light coloured grains were enriched in both La and $\mathrm{Mn}$ (Figure 8). 


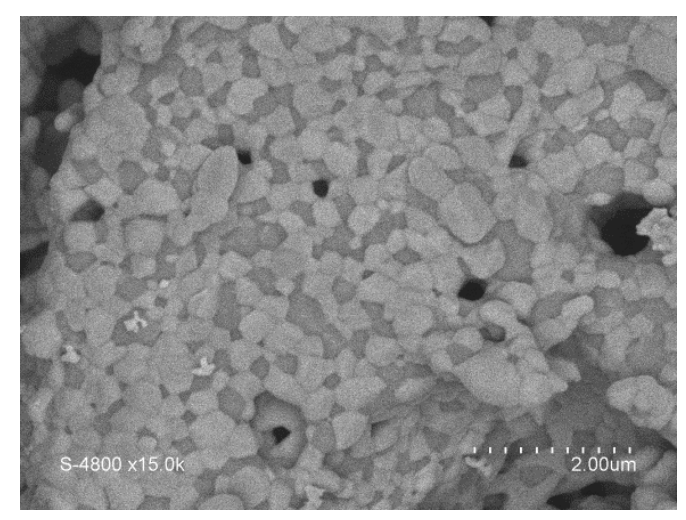

Figure 8: HDBSD image of LSMAl-P1 powder obtained at $1400^{\circ} \mathrm{C}$.

The results of EDX mapping representative for element migration in LSMAl-P1 are shown in Figure S4. The instability of the polymer matrix combustion reaction with localized ignition certainly promotes the migration/aggregation of elements in the P1-method. This uncontrolled behavior affects the powder homogeneity, favors the formation of defects during shaping and impedes the sintering processes. In the P1 powder series, a uniform composition was found for LSMMg-P1 obtained at $1400^{\circ} \mathrm{C}$. This homogeneity is related to the stabilizing effect of the $\mathrm{Mg}$ element, as already reported in the literature [21,41].

Homogeneous composition (no dopant segregation or migration) was evidenced by EDX mapping for all P2 powders obtained at $1400^{\circ} \mathrm{C}$ (Figure S5-S7), including LSMAl-P2 which exhibits a single type of grain.

For all powders except of LSMAl-P1, the EDX derived compositions are close to the expected values (Table S8). However, an efficient milling step is recommended for ensuring uniform powder characteristics before any utilization/application of the P1-powders, whereas a mild disaggregation step is sufficient for P2-powders.

In summary, the comparison of morphology, microstructure and structure of the P1 and P2 powders obtained at either $600^{\circ} \mathrm{C}$ or $1400^{\circ} \mathrm{C}$ emphasizes the strong influence of the Pechini parameters on powders homogeneity and sinterability. The $\mathrm{P} 2$ powders obtained at $600^{\circ} \mathrm{C}$ were found to be uniform in both morphology and composition, with high specific surface area and a 
well-defined cubic perovskite structure. These powders can be easily shaped as pellets and their sintering is controllable up to strong densification at about $1400^{\circ} \mathrm{C}$.

\subsection{Comparison of the redox activity of $\mathrm{P} 1$ and $\mathrm{P} 2$ powders}

When the P1 and P2 powder series were thermally treated at $1400^{\circ} \mathrm{C}$, both their specific surface area and main crystalline phase became comparable. Hence, their performance for $\mathrm{CO} 2$ splitting is expected to be similar. The results of TGA (Figure 9) for two successive redox cycles are reported in Table 4 for LSM, LSMAl and LSMMg powders prepared by both P1 and P2 methods at $1400^{\circ} \mathrm{C}$. The $\mathrm{O} 2 / \mathrm{CO}$ production and re-oxidation yields are compared.

Table 4: Comparison of $\mathrm{O}_{2}$ and $\mathrm{CO}$ production and reoxidation yield during two redox cycles (TGA analyses) for LSM-based powders (with or without Al or Mg dopants) obtained at $1400^{\circ} \mathrm{C}$ by $P 1$ or $P 2$ method.

\begin{tabular}{|c|ccc|ccc|}
\cline { 2 - 7 } \multicolumn{1}{c|}{} & \multicolumn{3}{c|}{$\mathbf{1}^{\text {st }}$ cycle } & \multicolumn{3}{c|}{$\mathbf{2}^{\text {nd }}$ cycle } \\
Sample & $\begin{array}{c}\mathrm{O}_{2} \\
\text { production } \\
(\mu \mathrm{mol} / \mathrm{g})\end{array}$ & $\begin{array}{c}\mathrm{CO} \\
\text { production } \\
(\mu \mathrm{mol} / \mathrm{g})\end{array}$ & $\begin{array}{c}\text { Re- } \\
\text { oxidation } \\
\text { yield }(\%)\end{array}$ & $\begin{array}{c}\mathrm{O}_{2} \\
\text { production } \\
(\mu \mathrm{mol} / \mathrm{g})\end{array}$ & $\begin{array}{c}\mathrm{CO} \\
\text { production } \\
(\mu \mathrm{mol} / \mathrm{g})\end{array}$ & $\begin{array}{c}\text { Re- } \\
\text { oxidation } \\
\text { yield }(\%)\end{array}$ \\
\hline LSM-P1 & 193 & 184 & 48 & 161 & 185 & 57 \\
\hline LSM-P2 & 232 & 190 & 41 & 104 & 195 & 94 \\
\hline LSMA1-P1 & 310 & 198 & 32 & 129 & 212 & 82 \\
\hline LSMAl-P2 & 302 & 200 & 33 & 109 & 203 & 93 \\
\hline LSMMg-P1 & 287 & 219 & 38 & 112 & 217 & 97 \\
\hline LSMMg-P2 & 269 & 214 & 40 & 111 & 215 & 97 \\
\hline
\end{tabular}

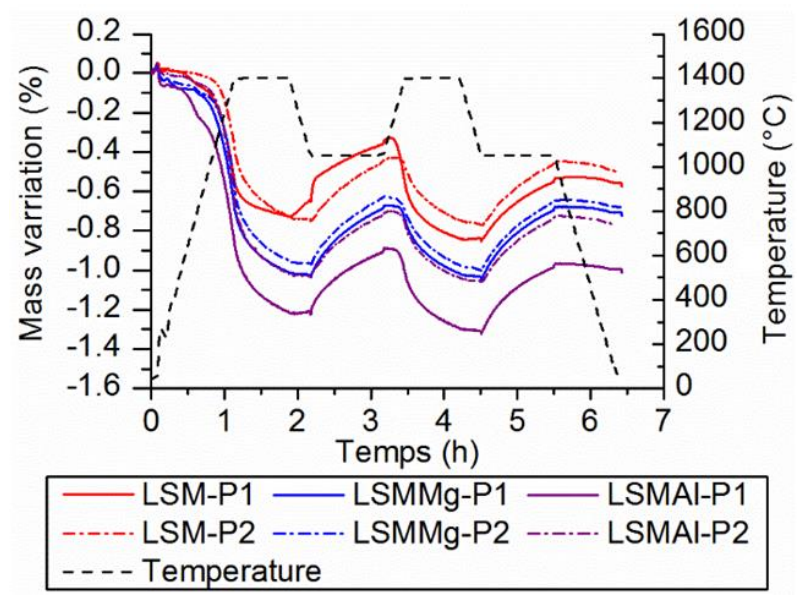


Figure 9: Thermogravimetric analysis of two redox cycles for $\mathrm{CO}_{2}$ splitting with LSM-based powders (with or without Al or Mg dopants) obtained at $1400^{\circ} \mathrm{C}$.

The TGA measurements show that both $\mathrm{P} 1$ and P2 powders exhibit similar fuel production yield during the two step thermochemical cycles. However, slight differences were noticed depending on the dopant. The highest CO amount $(215-217 \mu \mathrm{mol} / \mathrm{g})$ was produced by LSMMg powders with an almost complete re-oxidation for both $\mathrm{P} 1$ and P2 powders (97\%), thereby confirming cycling stability. For all samples, the $\mathrm{CO}$ production yield during the first and second cycle was similar. It is important to note the very low re-oxidation of LSM-P1 due to an incomplete reduction of the material after the first cycle. In fact, the mass loss for SLM-P1 did not reach equilibrium after the first reduction step, as the second reduction step led to higher final mass decrease. In contrast, the global mass loss during the first and second reduction was similar for the other tested materials.

These results clearly demonstrate that the reactivity of the LSM-based powders is not altered by the synthesis protocol, despite strongly different sintering behavior of the P1 and P2 derived powders. The powders stabilization at $1400{ }^{\circ} \mathrm{C}$ before the redox cycling experiment is the key asset to provide comparable characteristics. Thus, even if an intermediate multiphasic structure was noticed for $\mathrm{P} 1$ samples between 600 and $1200{ }^{\circ} \mathrm{C}$, a unique perovskite phase is obtained at $1400{ }^{\circ} \mathrm{C}$ (especially after ageing in $\mathrm{CO}_{2}$ splitting cycles), ensuring similar redox activity for both $\mathrm{P} 1$ and $\mathrm{P} 2$ powders.

This statement represents a real advantage concerning the shaping processes of powders for two step thermochemical cycling. In fact it offers the possibility to control the sintering/densification without altering the perovskite redox reactivity (at temperatures $\sim 1400{ }^{\circ} \mathrm{C}$ ) but also it enables the selection of the most suitable synthesis method for the targeted redox oxide design and shaping (powder, porous monolith, or dense membrane). 
Even though using more organics in the $\mathrm{P} 2$ process is less ecofriendly, it provides a better control over the reaction between the metal salts and the organic fuel (without any explosive and selfsustaining combustion at $200^{\circ} \mathrm{C}$ ). In addition such perovskite powders feature more homogeneous composition, microstructure and crystalline structure at lower temperature.

It has to be noticed that dense ceramic materials offer limited access/release of gases through the material volume (bulk). Hence, the reactivity of fully sintered pellets is expected to be extremely low with respect to $\mathrm{CO}$ production and re-oxidation yield (oxidation will be mostly restricted to the external surface). In order to confirm this hunch, an additional TGA experiment has been performed on the LSM-P2 dense material sintered at $1550^{\circ} \mathrm{C}$. As expected (results not shown), the dense material exhibit very low reduction and re-oxydation extents (17 and $12 \mu \mathrm{mol} / \mathrm{g}$, respectively), due to the difficult release of oxygen from such dense sample.

\subsection{Influence of dopants on the redox activity of sinterable P2 powders}

Composition engineering of the perovskite material has been proven critical to achieve improved redox efficiency and long-term cycling stability. In order to further improve the performance of the attractive sinterable P2 powders, additional formulations have been investigated: $(\mathrm{La}, \mathrm{Sr})(\mathrm{Mn}, \mathrm{X}) \mathrm{O}_{3}$ and $(\mathrm{La}, \mathrm{Ca})(\mathrm{Mn}, \mathrm{X}) \mathrm{O}_{3}$ with $\mathrm{X}=\mathrm{Al}, \mathrm{Mg}, \mathrm{Ga}$ or $\mathrm{Cr}$. The characteristics and performance of these powders are compared in Table 5. The TGA curves during two successive redox cycles for $\mathrm{CO}_{2}$ splitting with the $\mathrm{Ca}$ - and $\mathrm{Sr}$-based perovskite powder series are compared in Figure 10. 
Table 5: Comparison of $\mathrm{O}_{2}$ and $\mathrm{CO}$ production and re-oxidation yield during two successive redox cycles (TGA analysis) for $(\mathrm{La}, \mathrm{Sr})(\mathrm{Mn}, \mathrm{X}) \mathrm{O}_{3}$ and $(\mathrm{La}, \mathrm{Ca})(\mathrm{Mn}, \mathrm{X}) \mathrm{O}_{3}$ powders obtained at $1400^{\circ} \mathrm{C}$ by $\mathrm{P} 2$ method $(\mathrm{X}=\mathrm{Al}, \mathrm{Mg}$, Ga or $\mathrm{Cr})$.

\begin{tabular}{|c|ccc|ccc|}
\hline \multirow{2}{*}{ Sample } & \multicolumn{3}{|c|}{$\mathbf{1}^{\text {st }}$ cycle } & \multicolumn{3}{c|}{$\mathbf{2}^{\text {nd }}$ cycle } \\
\cline { 2 - 7 } & $\begin{array}{c}\mathrm{O}_{2} \\
\text { production } \\
(\mu \mathrm{mol} / \mathrm{g})\end{array}$ & $\begin{array}{c}\mathrm{CO} \\
\text { production } \\
(\mu \mathrm{mol} / \mathrm{g})\end{array}$ & $\begin{array}{c}\text { Re- } \\
\text { oxidation } \\
\text { yield }(\%)\end{array}$ & $\begin{array}{c}\mathrm{O}_{2} \\
\text { production } \\
(\mu \mathrm{mol} / \mathrm{g})\end{array}$ & $\begin{array}{c}\mathrm{CO} \\
\text { production } \\
(\mu \mathrm{mol} / \mathrm{g})\end{array}$ & $\begin{array}{c}\text { Re- } \\
\text { oxidation } \\
\text { yield }(\%)\end{array}$ \\
\hline LCM-P2 & 325 & 175 & $27 \%$ & 107 & 182 & $85 \%$ \\
\hline LCMAl-P2 & 449 & 162 & $18 \%$ & 95 & 171 & $90 \%$ \\
\hline LCMMg-P2 & 394 & 154 & $20 \%$ & 121 & 173 & $71 \%$ \\
\hline LCMGa-P2 & 267 & 215 & $40 \%$ & 175 & 200 & $57 \%$ \\
\hline LCMCr-P2 & 249 & 111 & $22 \%$ & 78 & 125 & $80 \%$ \\
\hline LSM-P2 & 232 & 190 & $41 \%$ & 104 & 195 & $94 \%$ \\
\hline LSMA1-P2 & 302 & 200 & $33 \%$ & 109 & 203 & $93 \%$ \\
\hline LSMMg-P2 & 269 & 214 & $40 \%$ & 111 & 215 & $97 \%$ \\
\hline LSMGa-P2 & 231 & 195 & $42 \%$ & 101 & 196 & $97 \%$ \\
\hline LSMCr-P2 & 215 & 134 & $31 \%$ & 76 & 139 & $91 \%$ \\
\hline
\end{tabular}
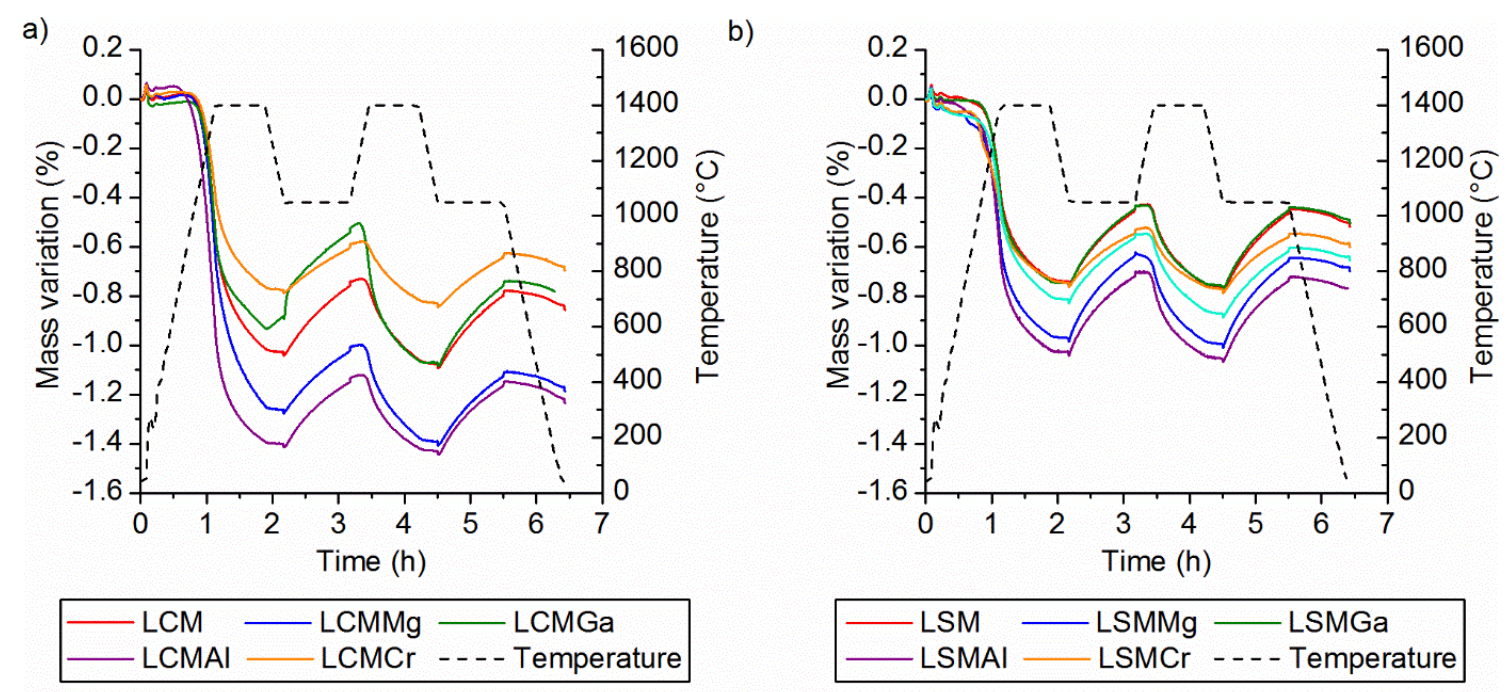

Figure 10: Thermogravimetric analysis of two redox cycles for $\mathrm{CO}_{2}$ splitting with a) Ca-based perovskite series (P2 method), and b) Sr-based perovskite series (P2 method).

Stable CO productions during the first and second cycles were obtained for the Ca-based perovskites. In addition, their reduction extent was higher than for Sr-based perovskites. The highest reduction extent during the first cycle was observed for LCMAl-P2, while the highest 
reduction extent during the second cycle was evidenced for LCMGa-P2 (175 $\mu \mathrm{mol} / \mathrm{g})$. Reduction of LCMGa-P2 did not seem to reach its final equilibrium after the first cycle, as revealed by the important quantity of $\mathrm{O}_{2}$ produced during the second reduction. For each perovskite, similar $\mathrm{CO}$ productions were measured during the first and second cycles, revealing a stable production. The LCMCr-P2 sample provided weaker CO production $(125 \mu \mathrm{mol} / \mathrm{g})$ compared to LCM-P2 (182 $\mu \mathrm{mol} / \mathrm{g})$. The CO production for LCMGa-P2 $(200 \mu \mathrm{mol} / \mathrm{g})$, LCMMg-P2 $(173 \mu \mathrm{mol} / \mathrm{g})$ and LCMAl-P2 (171 $\mu \mathrm{mol} / \mathrm{g})$ was similar to the one of LCM-P2. The Ca-doped perovskites exhibited lower re-oxidation yields in comparison with Sr-doped samples, with a maximum of $90 \%$ for LCMAl-P2. These results can be explained by low oxidation rates, consistent with the lower maximal CO production yield measured for the Ca-based perovskites (Table 6).

Table 6: Comparison of $\mathrm{O}_{2}$ and $\mathrm{CO}$ peak production rates during two redox cycles for $\mathrm{CO}_{2}$ splitting with Ca and Sr-doped perovskite series (P2 method).

\begin{tabular}{|c|cc|cc|}
\hline \multirow{2}{*}{ Sample } & \multicolumn{2}{|c|}{$\mathbf{1}^{\text {st }}$ cycle } & \multicolumn{2}{c|}{ 2 $^{\text {nd }}$ cycle } \\
\cline { 2 - 5 } & $\begin{array}{c}\mathrm{O}_{2} \text { production peak } \\
(\mu \mathrm{mol} / \mathrm{g} / \mathrm{min})\end{array}$ & $\begin{array}{c}\text { CO production peak } \\
(\mu \mathrm{mol} / \mathrm{g} / \mathrm{min})\end{array}$ & $\begin{array}{c}\mathrm{O}_{2} \text { production peak } \\
(\mu \mathrm{mol} / \mathrm{g} / \mathrm{min})\end{array}$ & $\begin{array}{c}\text { CO production peak } \\
(\mu \mathrm{mol} / \mathrm{g} / \mathrm{min})\end{array}$ \\
\hline LSM-P2 & 12.5 & 6.1 & 5.8 & 6.5 \\
\hline LSMAl-P2 & 15.6 & 8.9 & 6.7 & 6.4 \\
\hline LSMMg-P2 & 14.1 & 9.6 & 5.7 & 7.2 \\
\hline LSMGa-P2 & 12.7 & 6.1 & 6.1 & 6.2 \\
\hline LSMCr-P2 & 8.8 & 4.2 & 3.9 & 4.1 \\
\hline LCM-P2 & 16.9 & 4.5 & 4.8 & 4.8 \\
\hline LCMMg-P2 & 18.9 & 4.5 & 6.5 & 6.8 \\
\hline LCMGa-P2 & 17.1 & 25.9 & 12.2 & 5.4 \\
\hline LCMA1-P2 & 20.5 & 4.7 & 5.0 & 2.9 \\
\hline LCMCr-P2 & 12.3 & 2.9 & 3.2 & \\
\hline
\end{tabular}

Initially LCM-P2, LCMA1-P2, LCMGa-P2 and LCMMg-P2 powders have different Mn oxidation states (respectively $+3.50,+3.83,+3.63$ and +3.67 ) due to their different dopant content The calculation method is described in supplementary information. Mn oxidation state was not 
calculated for perovskites containing $\mathrm{Cr}$ that shows different oxidation states, which can interfere in the Mn oxidation state. After the first reduction, the Mn oxidation state reaches respectively $+3.25,+3.22,+3.36$, and +3.34 . LCMAl-P2 had a high initial Mn oxidation state compared to LCM-P2 and this fits the high amount of $\mathrm{O}_{2}$ produced during the reduction step. After reduction, the Mn oxidation state in LCMAl-P2 reached a value similar to the one obtained for LCM-P2. After the oxidation step, the Mn oxidation state is respectively $+3.32,+3.33,+3.47$ and +3.40 in the powder series. Due to incomplete re-oxidation, none of the samples was able to recover the initial Mn oxidation state. The final oxidation state was comparable for all samples thus explaining why similar $\mathrm{CO}$ productions were achieved within the sample series despite strong differences in the re-oxidation yields. These results suggest that the $\mathrm{CO}$ production capability is not directly governed by the final oxygen non-stoichiometry achieved (depending on the distinct oxygen vacancy formation capabilities of the compounds), but is rather directed by the final oxidation state of the redox-active Mn cation obtained after reduction.

Figure 11 presents the $\mathrm{O}_{2}$ production rate evolution for LCM-P2 perovskites during the first reduction step. All the production peaks occurred at the same time, when the heating ramp stopped, and the temperature became constant. LCMAl-P2 and LCMMg-P2 powders have a higher peak rate of $\mathrm{O}_{2}$ production than LCM one, whereas it is lower for LCMCr-P2 and LCMGa-P2. It is noticeable that all the reduction reactions start at $\sim 900^{\circ} \mathrm{C}$ (except for LCMAl-P2 showing an onset temperature approximately $200^{\circ} \mathrm{C}$ lower than LCM-P2). This suggests that LCMA1-P2 possesses a lower reduction enthalpy than other Ca-based perovskites, thus explaining the high reduction extent of LCMAl-P2 sample observed during the first cycle. 

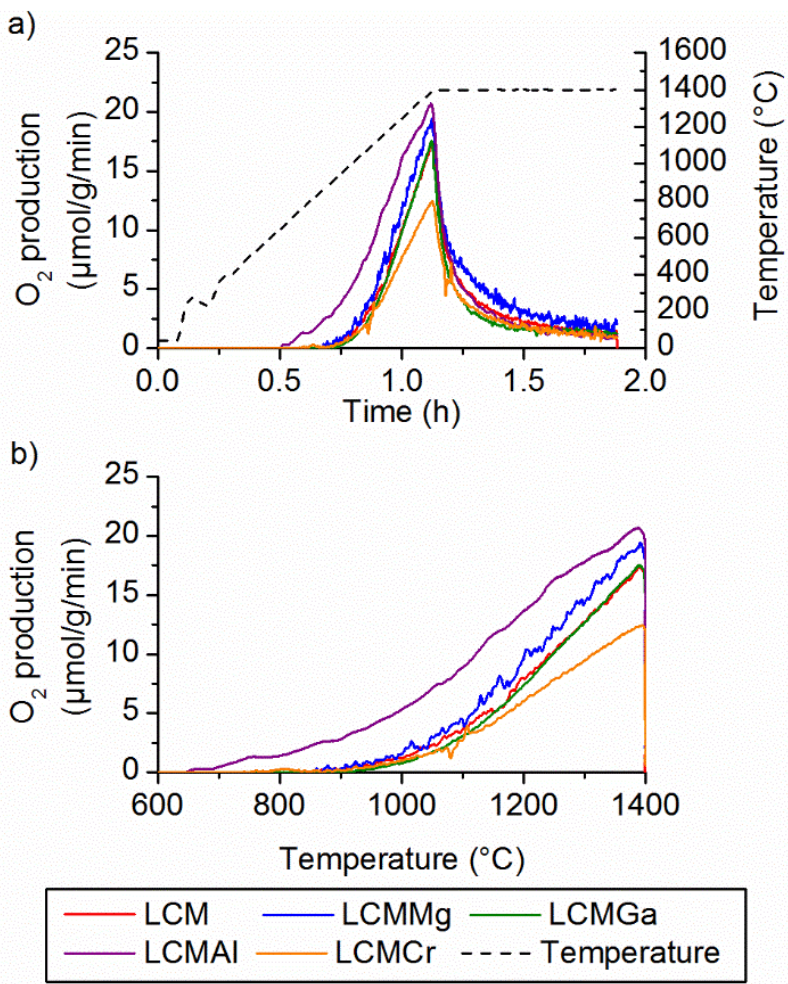

Figure 11: Evolution of (a) $\mathrm{O}_{2}$ production rate during the reduction step and (b) $\mathrm{O}_{2}$ production rate versus temperature, for LCM-based powders ( $P 2$ method) obtained at $1400^{\circ} \mathrm{C}$.

Similarly to the Ca-based perovskites, stable $\mathrm{CO}$ productions during the first and second cycles were obtained for the Sr-based perovskites. It can be noticed that the reduction extent was lower than for Ca-based perovskites. The highest reduction extent during the first cycle was observed for LSMAl-P2 $(302 \mu \mathrm{mol} / \mathrm{g})$. Except for the Cr-doped samples, $\mathrm{O}_{2}$ productions were comparable during the second reduction step. The differences mostly appear during the re-oxidation: $\mathrm{CO}$ production for LSM-P2 (195 $\mu \mathrm{mol} / \mathrm{g})$ is similar to LSMGa-P2 (196 $\mu \mathrm{mol} / \mathrm{g})$ and LSMAl-P2 (203 $\mu \mathrm{mol} / \mathrm{g})$. LSMMg-P2 exhibits slightly higher CO production $(215 \mu \mathrm{mol} / \mathrm{g})$ compared to LSM. For this second cycle, all the Sr-based perovskites present a re-oxidation yield higher than $90 \%$.

Initially, LSM-P2, LSMMg-P2, LSMGa-P2 and LSMA1-P2 have different Mn oxidation states (respectively $+3.50,3.67,3.63$ and 3.83 ) due to their different dopant contents. After the first reduction, the Mn oxidation states decrease to $+3.30,3.41,3.37$ and 3.42, respectively. After the oxidation step, the Mn oxidation states are $+3.38,3.36,3.48$ and 3.56, respectively. After the 
oxidation, none of the LSM-P2, LSMMg-P2, LSMGa-P2 and LSMAl-P2 samples recovers their initial Mn oxidation state.

Figure 12 presents the $\mathrm{O}_{2}$ production rate evolution for LSM-P2 during the first reduction step. For each sample, the main $\mathrm{O}_{2}$ production peak occurs at the end of the temperature ramp. Furthermore, LSMA1-P2 and LSMMg-P2 present a higher $\mathrm{O}_{2}$ production peak than LSM, whereas it is lower for LSMCr-P2 and LSMGa-P2.
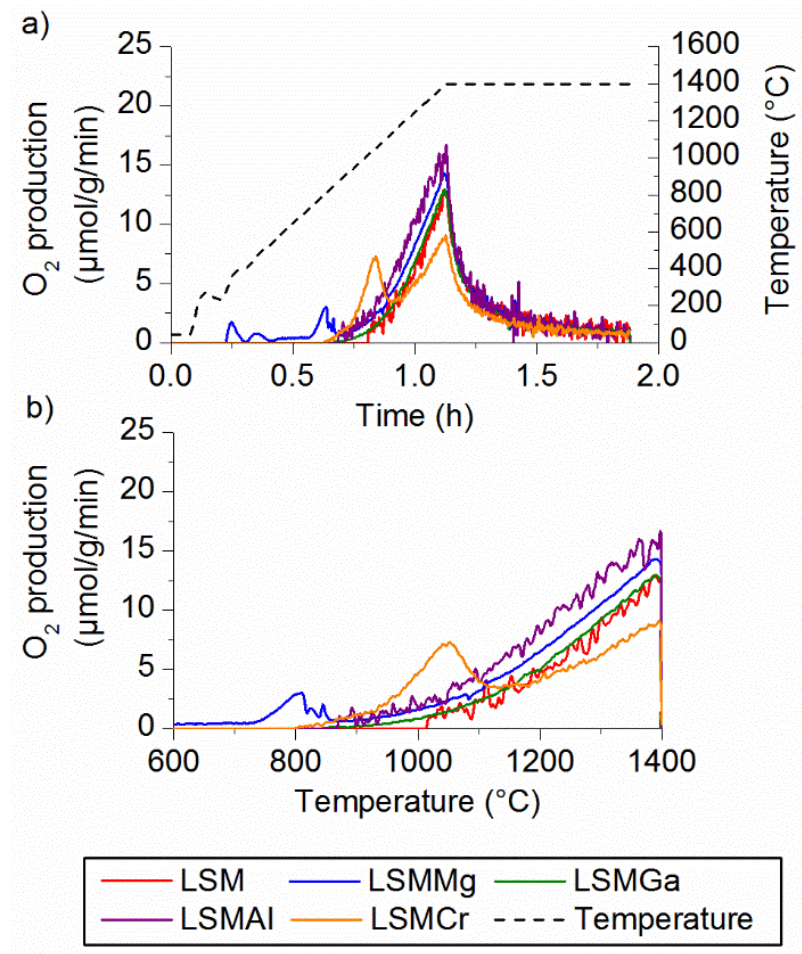

Figure 12: Evolution of (a) $\mathrm{O}_{2}$ production rate during reduction and (b) $\mathrm{O}_{2}$ production rate versus temperature for LSM-based powders (P2 method) obtained at $1400^{\circ} \mathrm{C}$.

To sum up, Ca-doped perovskites provide higher reduction extent than Sr-doped perovskites. Conversely, Sr-based perovskites show higher re-oxidation yield than Ca-based perovskites. The use of $\mathrm{Mg}$ dopant in $\mathrm{B}$ site is promising. In fact, $\mathrm{Mg}^{2+}$ is not involved in the redox reactions but it enhances the oxidation degree of $\mathrm{Mn}$ (compared with $\mathrm{Ga}^{3+}$ and $\mathrm{Al}^{3+}$ ), thus favoring both reduction and oxidation extents, and it also acts as a sintering inhibitor. Indeed, the LSMMg powder 
remains dispersed and not cohesive after TCC unlike the other powders that showed sintering phenomena.

\section{Conclusion}

A series of perovskite materials has been prepared using Pechini-derived protocols (P1 \& P2) with two sets of parameters. The physicochemical characteristics of the powders have been compared including their behavior during thermal treatment (sintering) and thermochemical $\mathrm{CO}_{2}$ splitting. Doping of A and B sites in the perovskites structure with a series of alkaline earth and transition metal cations respectively, was carried out to evaluate the impact of dopants on materials reactivity and cyclability, but also sinterability. The formation of minor secondary phases detected in LSM-P1 powders was reduced when using high concentration of organics (P2 method) able to ensure better ion dispersion in the polymer matrix. In spite of the microstructural differences between the pristine $\mathrm{P} 1$ and $\mathrm{P} 2$ powders prepared at $1400^{\circ} \mathrm{C}$, similar $\mathrm{CO}$ production yields were obtained during thermochemical redox cycling for $\mathrm{CO}_{2}$ splitting reaction. In fact, comparable structure and microstructure were evidenced for both $\mathrm{P} 1$ and $\mathrm{P} 2$ powders after the redox cycling at $1400^{\circ} \mathrm{C}$ in $\mathrm{CO}_{2}$.

Moreover, the selected synthesis protocol was found to be of prime importance for tuning the materials sinterability and shaping behavior. Indeed, undoped LSM-P1 powder exhibited very low sintering behavior in comparison with the high sinterability evidenced for P2 powders. This finding is a very attractive output for either considering the possible shaping of the LSM powder materials (LSM-P2) or ensuring the stability of initial powder microstructure (LSM-P1). In addition it has been found that both the synthesis protocol and the selected dopant influence the powder sinterability, without affecting its redox activity. Al-doped samples showed fast sintering at high temperature and similar final shrinkage whatever the synthesis protocols (P1 or P2). Gadoping provided similar redox behavior as undoped LSM whereas Cr-doping did not yield 
competitive results. Finally, Mg-doped powders exhibited the most attractive redox properties and also the highest resistance to shrinkage whatever the synthesis protocol used for their preparation. Hence, Mg-doping might be an asset to produce very stable free powders for thermochemical looping. As expected, Ca substitution on A-site promoted the reduction step and $\mathrm{O}_{2}$ production while limiting the re-oxidation step.

The results of the present structural and microstructural investigation of doped perovskite powders offer the opportunity to target different applications for these materials in thermochemical reactors depending on both their formulation and synthesis protocol. The LSM powders exhibiting the lowest dimensional changes with temperature could be used for applications in particle-based solar reactors, whereas sinterable powders should be preferred when a shaping step is required (monoliths, foams, or dense membranes) for their integration in a structured reactor for $\mathrm{CO}_{2}$ splitting.

\section{Authors Contributions}

Experimental work: J.J., A.H; Writing-Original Draft Preparation: J.J., A.H.; Writing-Review \& Editing: A.J., S.A., A.A., M.D.; Supervision: A.J., S.A.. All authors discussed the results and contributed to the final manuscript.

\section{Acknowledgements}

This study was supported by the French National Agency for Research (ANR, SUNFUEL project, contract $\mathrm{N}^{\circ}$ ANR-16-CE06-0010). The authors thank Didier COT and Bertrand REBIERE (Institut Européen des Membranes, Montpellier) for FESEM observations and EDX analyses and Dr. Bernard FRAISSE (Institut Charles Gerhart, Montpellier) for his helpful contribution to high temperature X-ray diffraction analyses. 


\section{Figure captions}

Figure 1: Dilatometric curves of LSM-based pellets derived from (a) P1- and (b) P2-powders obtained at $600^{\circ} \mathrm{C}$. Influence of $\mathrm{Al}$ and $\mathrm{Mg}$ dopants. The green density was in the range $30-35 \%$.

Figure 2: Room temperature XRD patterns of LSM-P1 powders obtained at different temperatures and after two thermochemical cycles with $\mathrm{Ar} / \mathrm{CO}_{2}$ (TCC). a) Whole pattern in the range $2 \theta=16$ $80^{\circ}$, b) Zoom in the range $2 \theta=23-40^{\circ}$.

Figure 3: High temperature XRD patterns $\left(2 \theta=25-56^{\circ}\right)$ of LSM-P1 powder, Co K $\alpha$ radiation $(\lambda=0.17903 \mathrm{~nm})$ from $600^{\circ} \mathrm{C}$ to $1500^{\circ} \mathrm{C}$ with a $100^{\circ} \mathrm{C}$ step.

Figure 4: Room temperature XRD patterns of LSM-P2 powders obtained at different temperatures and after two thermochemical cycles with $\mathrm{Ar} / \mathrm{CO}_{2}$ (TCC). a) Whole pattern in the range $2 \theta=16$ $80^{\circ}$, b) Zoom in the range $2 \theta=23-40^{\circ}$.

Figure 5: High temperature XRD patterns $\left(2 \theta=25-56^{\circ}\right)$ of LSM-P2 powder, Co K $\alpha$ radiation $(\lambda=0.17903 \mathrm{~nm})$ from $600^{\circ} \mathrm{C}$ to $1500^{\circ} \mathrm{C}$ with a $100^{\circ} \mathrm{C}$ step.

Figure 6: FESEM images of LSM-P1 powders obtained at $600^{\circ} \mathrm{C}$ (a) and $1400^{\circ} \mathrm{C}$ (b).

Figure 7: FESEM images of LSM-P2 powders obtained at $600^{\circ} \mathrm{C}$ (a) and $1400^{\circ} \mathrm{C}$ (b).

Figure 8: HDBSD image of LSMAl-P1 powder obtained at $1400^{\circ} \mathrm{C}$. 
Figure 9: Thermogravimetric analysis of two redox cycles for $\mathrm{CO}_{2}$ splitting with LSM-based powders (with or without $\mathrm{Al}$ or $\mathrm{Mg}$ dopants) obtained at $1400^{\circ} \mathrm{C}$.

Figure 10: Thermogravimetric analysis of two redox cycles for $\mathrm{CO}_{2}$ splitting with. a) Ca-based perovskite series (P2 method), and b) Sr-based perovskite series (P2 method).

Figure 11: Evolution of (a) $\mathrm{O}_{2}$ production rate during the reduction step and (b) $\mathrm{O}_{2}$ production rate versus temperature, for LCM-based powders ( $\mathrm{P} 2$ method) obtained at $1400^{\circ} \mathrm{C}$.

Figure 12: Evolution of (a) $\mathrm{O}_{2}$ production rate during reduction and (b) $\mathrm{O}_{2}$ production rate versus temperature for LSM-based powders (P2 method) obtained at $1400^{\circ} \mathrm{C}$. 


\section{Table captions:}

Table 1: Powders formulations, synthesis methods and samples references.

Table 2: Specific surface area of LSM-based powders obtained at $600^{\circ} \mathrm{C}$ and $1400^{\circ} \mathrm{C}$ by $\mathrm{P} 1$ and P2 methods. Influence of $\mathrm{Al}$ and $\mathrm{Mg}$ dopants.

Table 3: Grain sizes measured by FESEM for LSM-based powders obtained at $600^{\circ} \mathrm{C}$ and $1400^{\circ} \mathrm{C}$. Influence of $\mathrm{Al}$ and $\mathrm{Mg}$ dopants.

Table 4: Comparison of $\mathrm{O}_{2}$ and $\mathrm{CO}$ production and reoxidation yield during two redox cycles (TGA analyses) for LSM-based powders (with or without $\mathrm{Al}$ or $\mathrm{Mg}$ dopants) obtained at $1400^{\circ} \mathrm{C}$ by $\mathrm{P} 1$ or $\mathrm{P} 2$ method.

Table 5: Comparison of $\mathrm{O}_{2}$ and $\mathrm{CO}$ production and re-oxidation yield during two successive redox cycles (TGA analysis) for $(\mathrm{La}, \mathrm{Sr})(\mathrm{Mn}, \mathrm{X}) \mathrm{O}_{3}$ and $(\mathrm{La}, \mathrm{Ca})(\mathrm{Mn}, \mathrm{X}) \mathrm{O}_{3}$ powders obtained at $1400^{\circ} \mathrm{C}$ by $\mathrm{P} 2$ method $(\mathrm{X}=\mathrm{Al}, \mathrm{Mg}, \mathrm{Ga}$ or $\mathrm{Cr})$.

Table 6: Comparison of $\mathrm{O}_{2}$ and $\mathrm{CO}$ peak production rates during two redox cycles for $\mathrm{CO}_{2}$ splitting with Ca and Sr-doped perovskite series (P2 method). 


\section{References}

[1] N.S. Lewis, D.G. Nocera, Powering the planet: Chemical challenges in solar energy utilization, Proc. Natl. Acad. Sci. 103 (2006) 15729-15735. doi:10.1073/pnas.0603395103.

[2] C. Graves, S.D. Ebbesen, M. Mogensen, K.S. Lackner, Sustainable hydrocarbon fuels by recycling $\mathrm{CO} 2 \mathrm{and} \mathrm{H} 2 \mathrm{O}$ with renewable or nuclear energy, Renew. Sustain. Energy Rev. 15 (2011) 1-23. doi:10.1016/j.rser.2010.07.014.

[3] G. Centi, S. Perathoner, Opportunities and prospects in the chemical recycling of carbon dioxide to fuels, Catal. Today. 148 (2009) 191-205. doi:10.1016/j.cattod.2009.07.075.

[4] S. Abanades, M. Chambon, $\mathrm{CO} 2$ dissociation and upgrading from two-step solar thermochemical processes based on $\mathrm{ZnO} / \mathrm{Zn}$ and $\mathrm{SnO} 2 / \mathrm{SnO}$ redox pairs, Energy and Fuels. 24 (2010) 6667-6674. doi:10.1021/ef101092u.

[5] S. Abanades, A. Legal, A. Cordier, G. Peraudeau, G. Flamant, A. Julbe, Investigation of reactive cerium-based oxides for $\mathrm{H} 2$ production by thermochemical two-step watersplitting, J. Mater. Sci. 45 (2010) 4163-4173. doi:10.1007/s10853-010-4506-4.

[6] F. Call, M. Roeb, M. Schmücker, C. Sattler, R. Pitz Paal, Ceria doped with zirconium and lanthanide oxides to enhance solar thermochemical production of fuels, J. Phys. Chem. C. 119 (2015) 6929-6938. doi:10.1021/jp508959y.

[7] T. Kodama, Y. Kondoh, R. Yamamoto, H. Andou, N. Satou, Thermochemical hydrogen production by a redox system of $\mathrm{ZrO} 2$-supported $\mathrm{Co}(\mathrm{II})$-ferrite, Sol. Energy. 78 (2005) 623-631. doi:https://doi.org/10.1016/j.solener.2004.04.008. 
[8] J.E. Miller, M.D. Allendorf, R.B. Diver, L.R. Evans, N.P. Siegel, J.N. Stuecker, Metal oxide composites and structures for ultra-high temperature solar thermochemical cycles, J. Mater. Sci. 43 (2008) 4714-4728. doi:10.1007/s10853-007-2354-7.

[9] P.G. Loutzenhiser, M.E. Galvez, I. Hischier, A. Stamatiou, A. Frei, A. Steinfeld, CO2 splitting via two-step solar thermochemical cycles with $\mathrm{Zn} / \mathrm{ZnO}$ and $\mathrm{FeO} / \mathrm{Fe} 3 \mathrm{O} 4$ redox reactions II: Kinetic analysis, Energy and Fuels. 23 (2009) 2832-2839. doi:10.1021/ef801142b.

[10] C. Agrafiotis, A. Zygogianni, C. Pagkoura, M. Kostoglou, A.G. Konstandopoulos, Hydrogen production via solar-aided water splitting thermochemical cycles with nickel ferrite: Experiments and modeling, AIChE J. 59 (2013) 1213-1225. doi:10.1002/aic.13882.

[11] C. Milone, Y. Kato, E. Mastronardo, Thermal Energy Storage with Chemical Reactions, in: A. Frazzica, L.F. Cabeza (Eds.), Recent Adv. Mater. Syst. Therm. Energy Storage An Introd. to Exp. Charact. Methods, Springer International Publishing, Cham, 2019: pp. 15-32. doi:10.1007/978-3-319-96640-3_3.

[12] B. Bulfin, J. Vieten, C. Agrafiotis, M. Roeb, C. Sattler, Applications and limitations of two step metal oxide thermochemical redox cycles; a review, J. Mater. Chem. A. 5 (2017) 18951-18966. doi:10.1039/C7TA05025A.

[13] A. Haeussler, S. Abanades, J. Jouannaux, A. Julbe, Non-Stoichiometric Redox Active Perovskite Materials for Solar Thermochemical Fuel Production: A Review, Catalysts. 8 (2018) 611. doi:10.3390/catal8120611.

[14] C.K. Yang, Y. Yamazaki, A. Aydin, S.M. Haile, Thermodynamic and kinetic assessments of strontium-doped lanthanum manganite perovskites for two-step 
thermochemical water splitting, J. Mater. Chem. A. 2 (2014) 13612-13623. doi:10.1039/c4ta02694b.

[15] M.E. Gálvez, R. Jacot, J. Scheffe, T. Cooper, G. Patzke, A. Steinfeld, Physico-chemical changes in $\mathrm{Ca}, \mathrm{Sr}$ and $\mathrm{Al}$-doped $\mathrm{La}-\mathrm{Mn}-\mathrm{O}$ perovskites upon thermochemical splitting of $\mathrm{CO}_{2}$ via redox cycling, Phys. Chem. Chem. Phys. 17 (2015) 6629-6634. doi:10.1039/C4CP05898D.

[16] A. Demont, S. Abanades, Solar thermochemical conversion of CO2 into fuel via twostep redox cycling of non-stoichiometric Mn-containing perovskite oxides, J. Mater. Chem. A. 3 (2015) 3536-3546. doi:10.1039/c4ta06655c.

[17] T. Cooper, J.R. Scheffe, M.E. Galvez, R. Jacot, G. Patzke, A. Steinfeld, Lanthanum Manganite Perovskites with Ca/Sr A-site and Al B-site Doping as Effective Oxygen Exchange Materials for Solar Thermochemical Fuel Production, Energy Technol. 3 (2015) 1130-1142. doi:10.1002/ente.201500226.

[18] L. Wang, M. Al-Mamun, Y.L. Zhong, L. Jiang, P. Liu, Y. Wang, H.G. Yang, H. Zhao, $\mathrm{Ca}^{2+}$ and $\mathrm{Ga}^{3+}$ doped $\mathrm{LaMnO}_{3}$ perovskite as a highly efficient and stable catalyst for two-step thermochemical water splitting, Sustain. Energy Fuels. 1 (2017) 1013-1017. doi:10.1039/C6SE00097E.

[19] A.H. McDaniel, E.C. Miller, D. Arifin, A. Ambrosini, E.N. Coker, R. O’Hayre, W.C. Chueh, J. Tong, Sr- and Mn-doped LaAlO3- $\delta$ for solar thermochemical H 2 and CO production, Energy Environ. Sci. 6 (2013) 2424-2428. doi:10.1039/c3ee41372a.

[20] S. Dey, B.S. Naidu, C.N.R. Rao, Beneficial effects of substituting trivalent ions in the B-site of $\mathrm{La} 0.5 \mathrm{Sr} 0.5 \mathrm{Mn} 1-\mathrm{xAxO} 3(\mathrm{~A}=\mathrm{Al}, \mathrm{Ga}, \mathrm{Sc})$ on the thermochemical generation of CO and H2from CO2and H2O, Dalt. Trans. 45 (2016) 2430-2435. 
doi:10.1039/c5dt04822b.

[21] M.M. Nair, S. Abanades, Insights into the Redox Performance of Non-stoichiometric Lanthanum Manganite Perovskites for Solar Thermochemical CO2Splitting, ChemistrySelect. 1 (2016) 4449-4457. doi:10.1002/slct.201601171.

[22] I. Ermanoski, N.P. Siegel, E.B. Stechel, A New Reactor Concept for Efficient SolarThermochemical Fuel Production, J. Sol. Energy Eng. 135 (2013) 31002. doi:10.1115/1.4023356.

[23] R. Müller, P. Haeberling, R.D. Palumbo, Further advances toward the development of a direct heating solar thermal chemical reactor for the thermal dissociation of $\mathrm{ZnO}(\mathrm{s})$, Sol. Energy. 80 (2006) 500-511. doi:10.1016/j.solener.2005.04.015.

[24] N. Gokon, S. Takahashi, H. Yamamoto, T. Kodama, New Solar Water-Splitting Reactor With Ferrite Particles in an Internally Circulating Fluidized Bed, J. Sol. Energy Eng. 131 (2009) 11007. doi:10.1115/1.3027511.

[25] W.C. Chueh, C. Falter, M. Abbott, D. Scipio, P. Furler, S.M. Haile, A. Steinfeld, Highflux solar-driven thermochemical dissociation of $\mathrm{CO} 2$ and $\mathrm{H} 2 \mathrm{O}$ using nonstoichiometric ceria, Science (80-. ). 330 (2010) 1797-1801. doi:10.1126/science.1197834.

[26] F.A. Costa Oliveira, M.A. Barreiros, S. Abanades, A.P.F. Caetano, R.M. Novais, R.C. Pullar, Solar thermochemical CO2 splitting using cork-templated ceria ecoceramics, J. CO2 Util. 26 (2018) 552-563. doi:10.1016/j.jcou.2018.06.015.

[27] M. Tou, R. Michalsky, A. Steinfeld, Solar-Driven Thermochemical Splitting of CO2 and In Situ Separation of CO and O2 across a Ceria Redox Membrane Reactor, Joule. 1 (2017) 146-154. doi:10.1016/J.JOULE.2017.07.015. 
[28] T.O.L. Sunde, T. Grande, M.A. Einarsrud, Modified pechini synthesis of oxide powders and thin films, in: L. Klein, M. Aparicio, A. Jitianu (Eds.), Handb. Sol-Gel Sci. Technol. Process. Charact. Appl., Springer International Publishing, Cham, 2018: pp. 1089-1118. doi:10.1007/978-3-319-32101-1_130.

[29] M. Pechini, Method of Preparing Lead and Alkaline Earth Titanates and, 1967. doi:10.9780/2249894X.

[30] S. Brunauer, P.H. Emmett, E. Teller, Adsorption of Gases in Multimolecular Layers, J. Am. Chem. Soc. 60 (1938) 309-319. doi:10.1021/ja01269a023.

[31] A.H. McDaniel, E.C. Miller, D. Arifin, A. Ambrosini, E.N. Coker, R. O’Hayre, W.C. Chueh, J. Tong, Sr- and Mn-doped LaAlO3 $-\delta$ for solar thermochemical $\mathrm{H} 2$ and $\mathrm{CO}$ production, Energy Environ. Sci. 6 (2013) 2424. doi:10.1039/c3ee41372a.

[32] A. Demont, S. Abanades, Solar thermochemical conversion of $\mathrm{CO}_{2}$ into fuel via twostep redox cycling of non-stoichiometric Mn-containing perovskite oxides, J. Mater. Chem. A. 3 (2015) 3536-3546. doi:10.1039/C4TA06655C.

[33] A. Demont, S. Abanades, E. Beche, Investigation of perovskite structures as oxygenexchange redox materials for hydrogen production from thermochemical two-step water-splitting cycles, J. Phys. Chem. C. 118 (2014) 12682-12692. doi:10.1021/jp5034849.

[34] M. Takacs, M. Hoes, M. Caduff, T. Cooper, J.R. Scheffe, A. Steinfeld, Oxygen nonstoichiometry, defect equilibria, and thermodynamic characterization of LaMnO3perovskites with Ca/Sr A-site and Al B-site doping, Acta Mater. 103 (2016) 700-710. doi:10.1016/j.actamat.2015.10.026.

[35] A.E. Danks, S.R. Hall, Z. Schnepp, The evolution of "sol-gel" chemistry as a technique 
for materials synthesis, Mater. Horizons. 3 (2016) 91-112. doi:10.1039/c5mh00260e.

[36] F. Zheng, Phase Behavior of Lanthanum Strontium Manganites, J. Electrochem. Soc. 146 (1999) 2810. doi:10.1149/1.1392012.

[37] S.T. Aruna, M. Muthuraman, K.C. Patil, Combustion synthesis and properties of strontium substituted lanthanum manganites La1-xSrxMnO3 $(0 \leq \mathrm{x} \leq 0.3)$, J. Mater. Chem. 7 (1997) 2499-2503. http://www.scopus.com/inward/record.url?eid=2-s2.00000150417\&partnerID=tZOtx3y1.

[38] M. Gaudon, F. Ansart, P. Stevens, A. Rousset, Synthesis and Characterization of La 1 $-\mathrm{x} \operatorname{Sr} \mathrm{x} \mathrm{MnO} 3+\delta$ Thin Films from Polymeric Precursors, J. New Mater. Mater. Electrochem. Syst. 61 (2002) 57-61. doi:10.1063/1.1807015.

[39] J. Tsay, T. Fang, Effects of Molar Ratio of Citric Acid to Cations and of pH Value on the Formation and Thermal-Decomposition Behavior of Barium Titanium Citrate, J. Am. Ceram. Soc. 82 (2004) 1409-1415. doi:10.1111/j.1151-2916.1999.tb01931.x.

[40] A.L.A. da Silva, L. da Conceição, a M. Rocco, M.M.V.M. Souza, Synthesis of Srdoped $\mathrm{LaMnO} 3$ and $\mathrm{LaCrO} 3$ powders by combustion method: structural characterization and thermodynamic evaluation, Cerâmica. 58 (2012) 521-528. doi:10.1590/S0366-69132012000400018.

[41] D.L. Meixner, R.A. Cutler, Sintering and mechanical characteristics of lanthanum strontium manganite, Solid State Ionics. 146 (2002) 273-284. doi:10.1016/S01672738(01)01027-X. 


\section{Supplementary information (SI)}
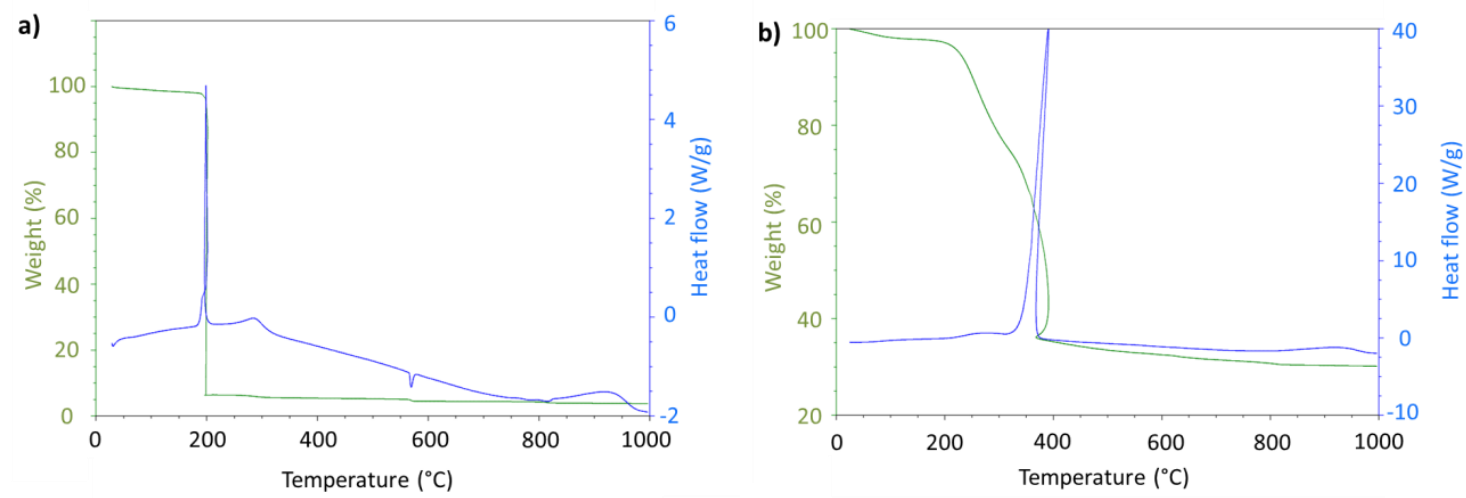

Figure S1: TGA/DSC curves $\left(5^{\circ} \mathrm{C} / \mathrm{min}\right.$ in air) corresponding to the formation of LSM-PI (a) and

LSM-P2 (b) powders by degradation/combustion of a polymeric resin. The P1-sample was pitched out from the platinum crucible during the explosive combustion, explaining why its final weight is near $0 \%$. 


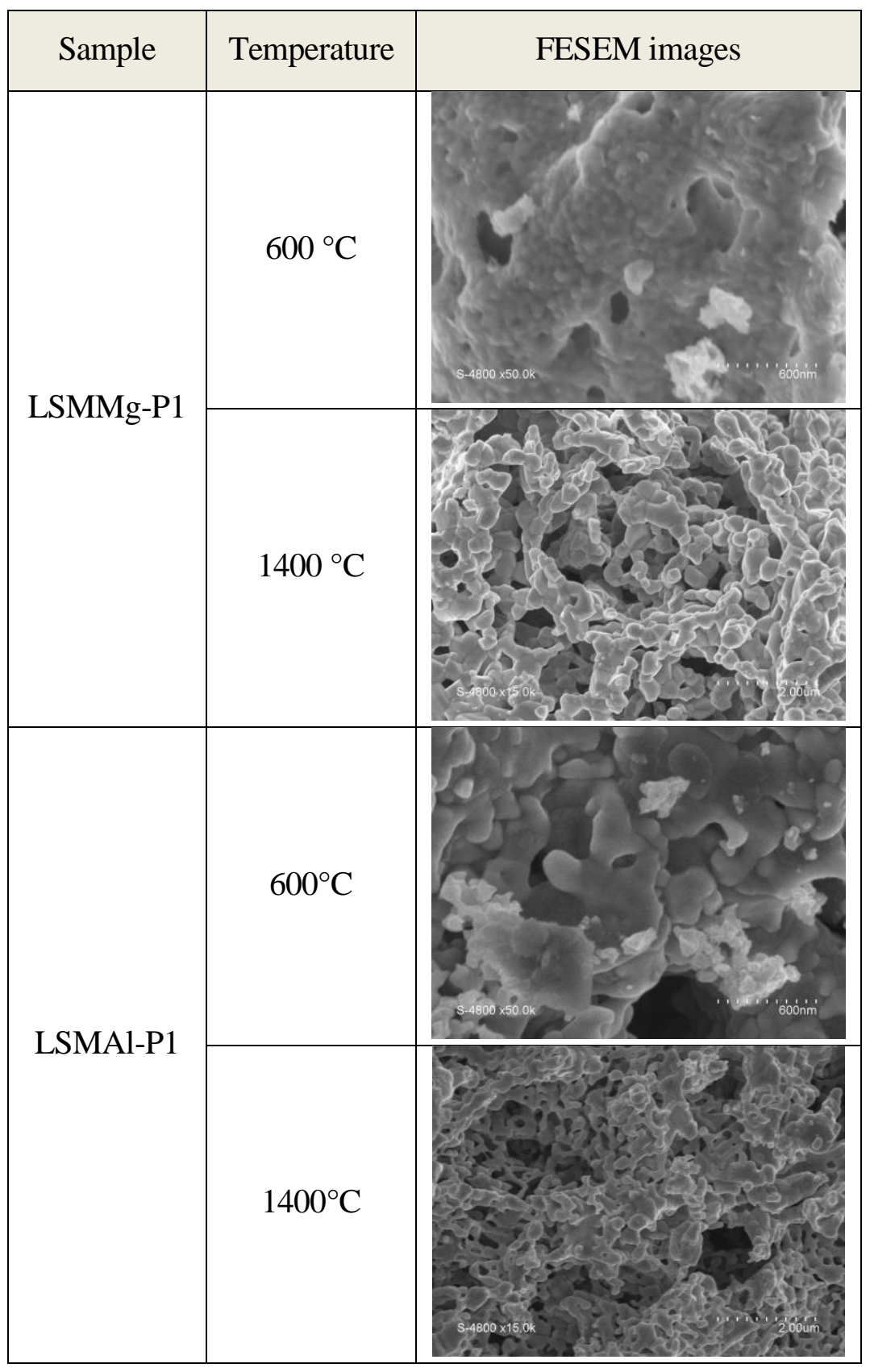

Figure S2: FESEM images of LSM-doped powders (LSMMg, LSMAl) obtained at either $600^{\circ} \mathrm{C}$ or $1400{ }^{\circ} \mathrm{C}$ with the $\mathrm{Pl}$ method. 


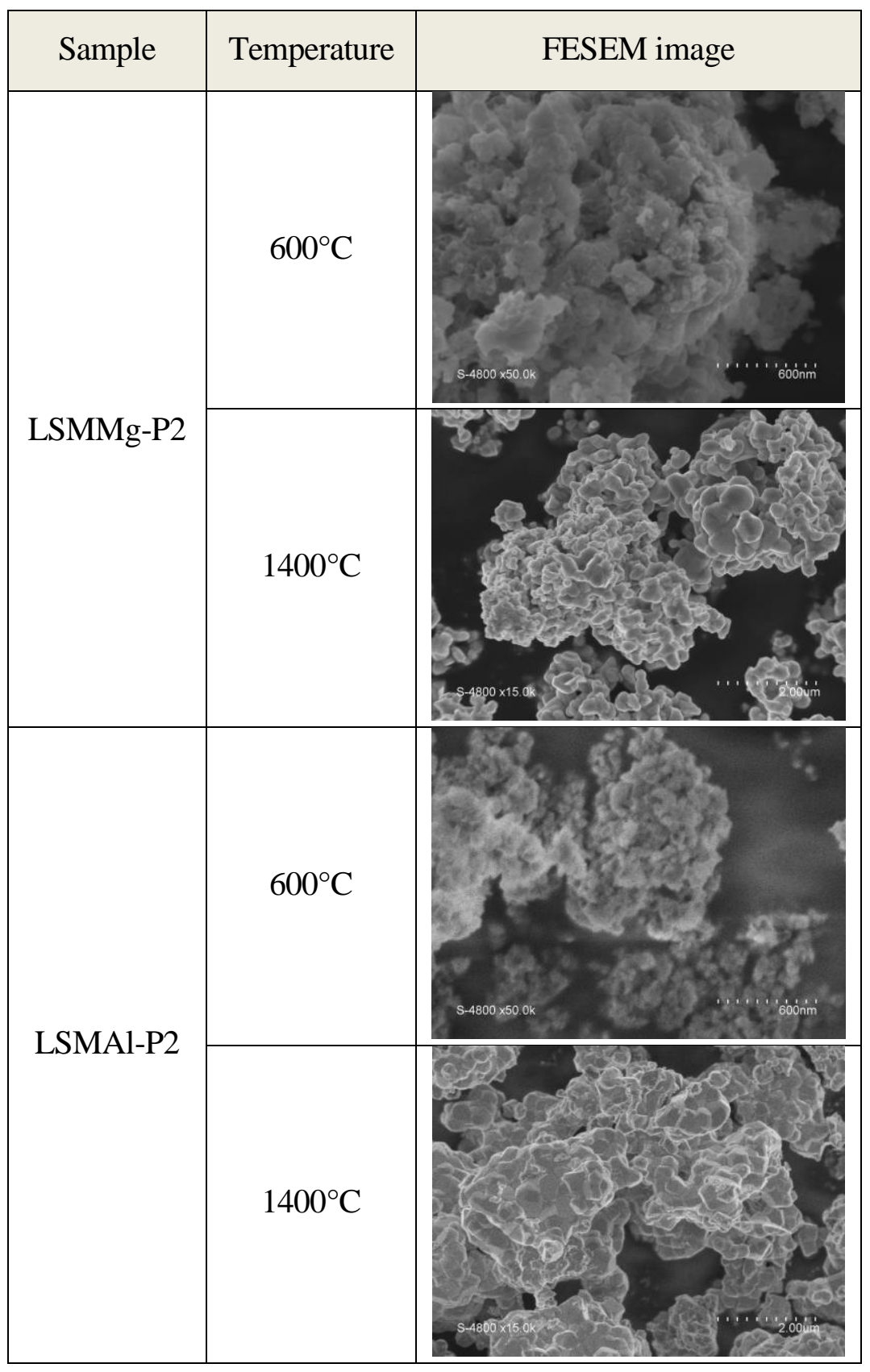

Figure S3: FESEM images of LSM-doped powders (LSMMg, LSMAl) obtained at either $600^{\circ} \mathrm{C}$ or $1400{ }^{\circ} \mathrm{C}$ with the $\mathrm{P} 2$ method. 

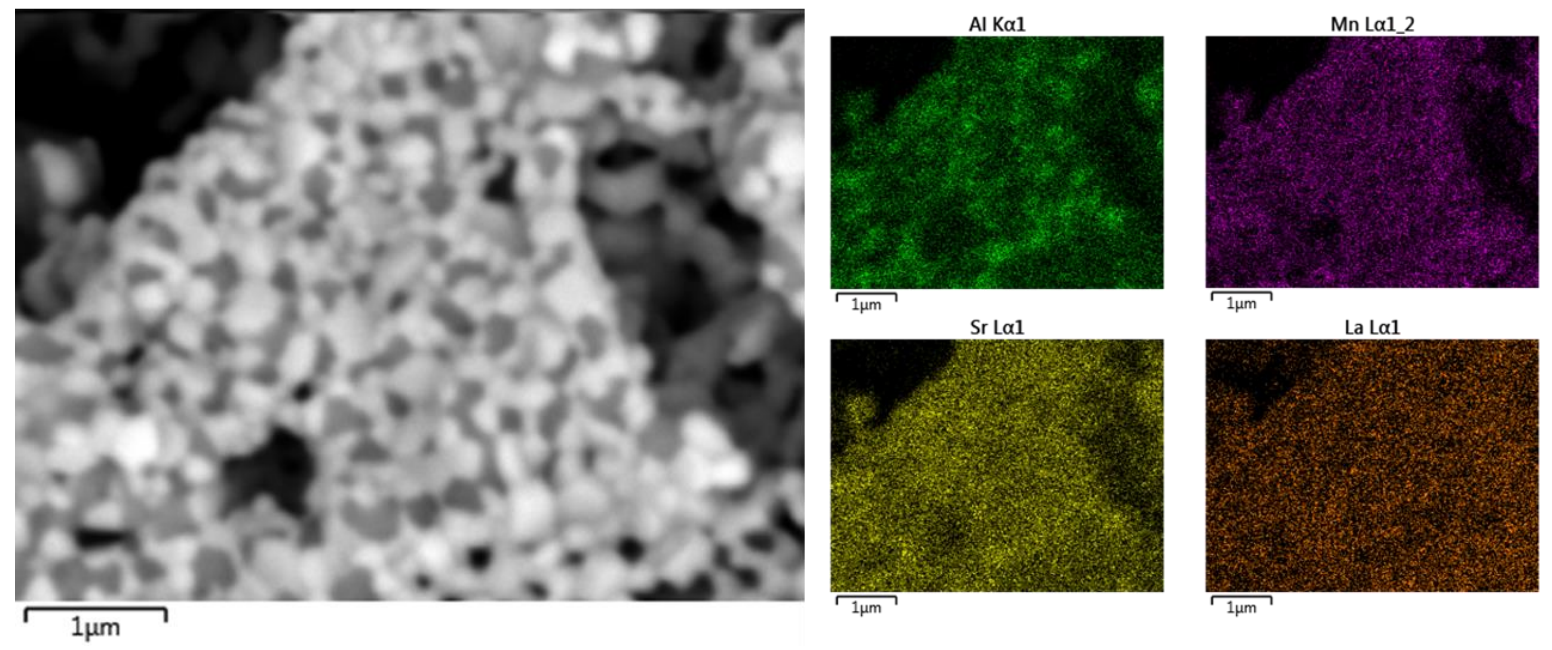

Figure S4: HDBSD image and EDX mapping of LSMAl-P1 powder obtained at $1400^{\circ} \mathrm{C}$. 

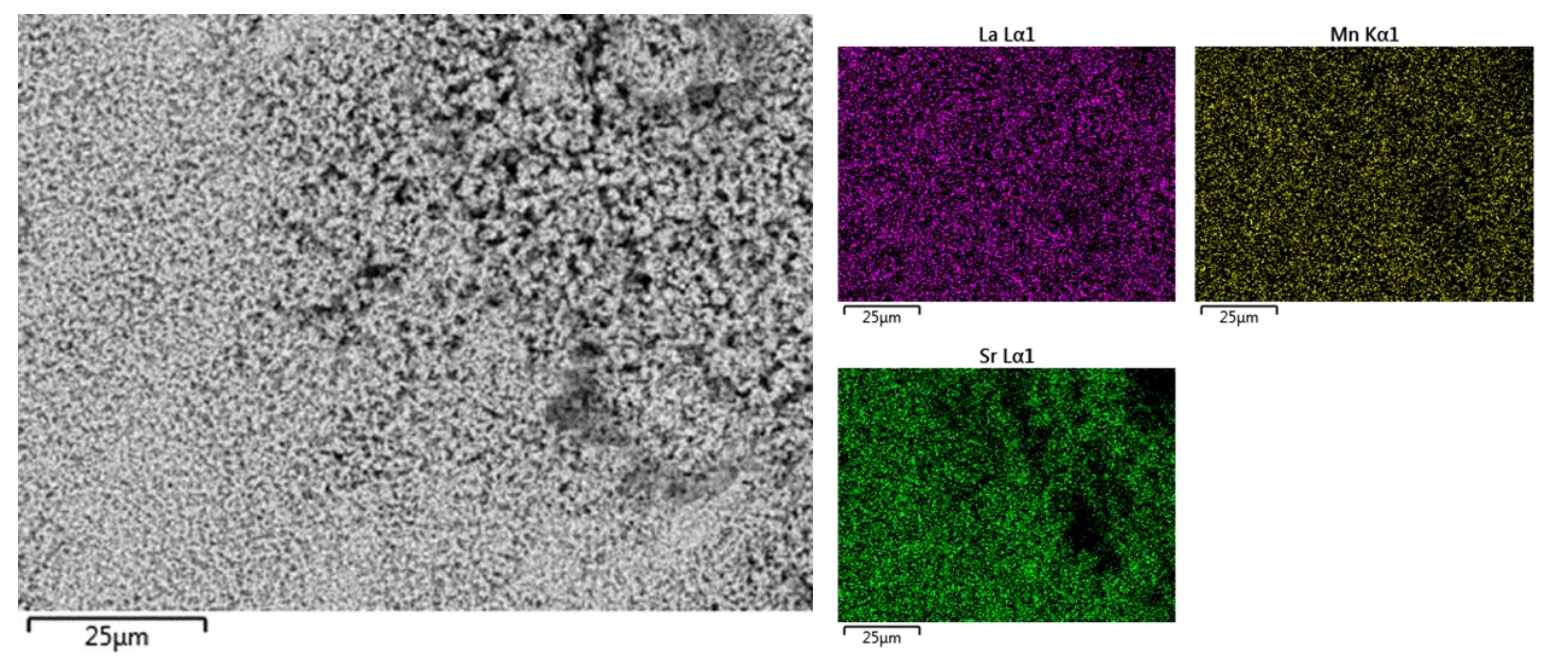

Figure S5: HDBSD image and EDX mapping of LSM-P2 powder obtained at $1400{ }^{\circ} \mathrm{C}$. 

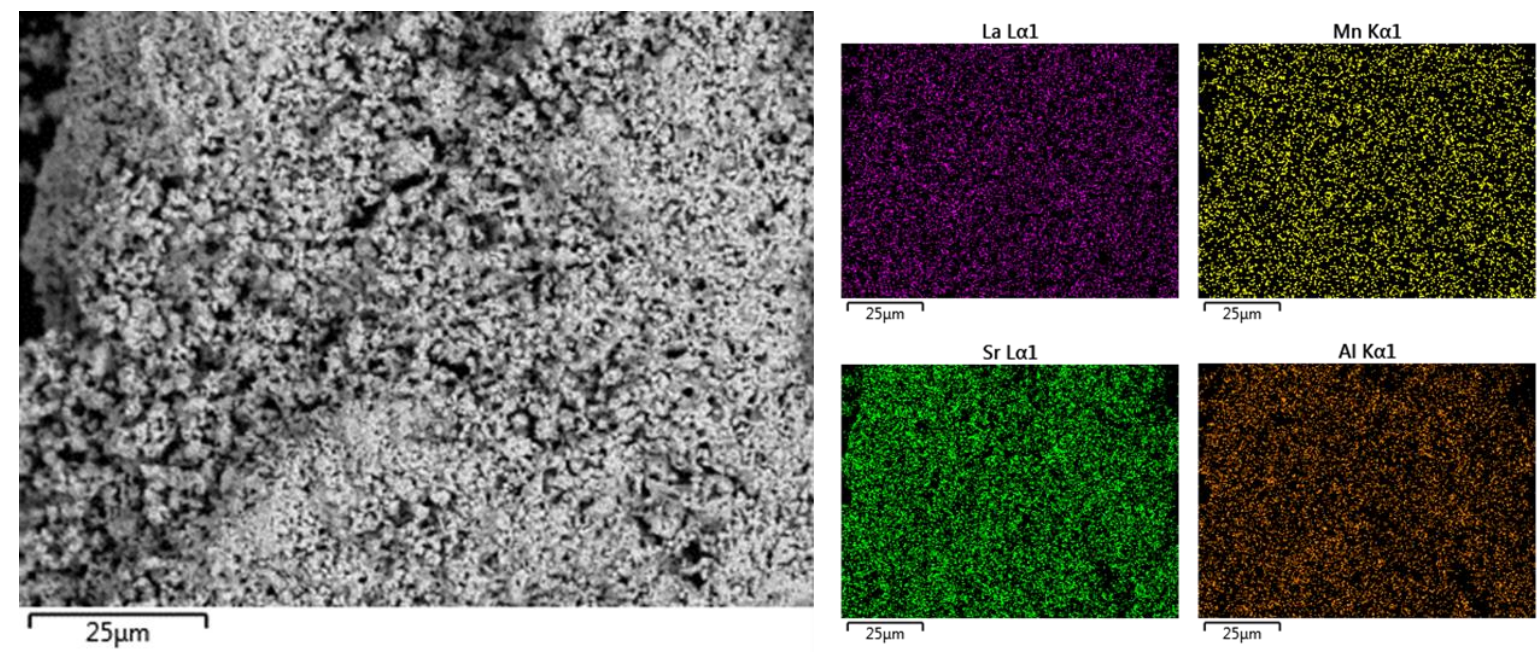

Figure S6: HDBSD image and EDX mapping of LSMAl-P2 powder obtained at $1400{ }^{\circ} \mathrm{C}$. 

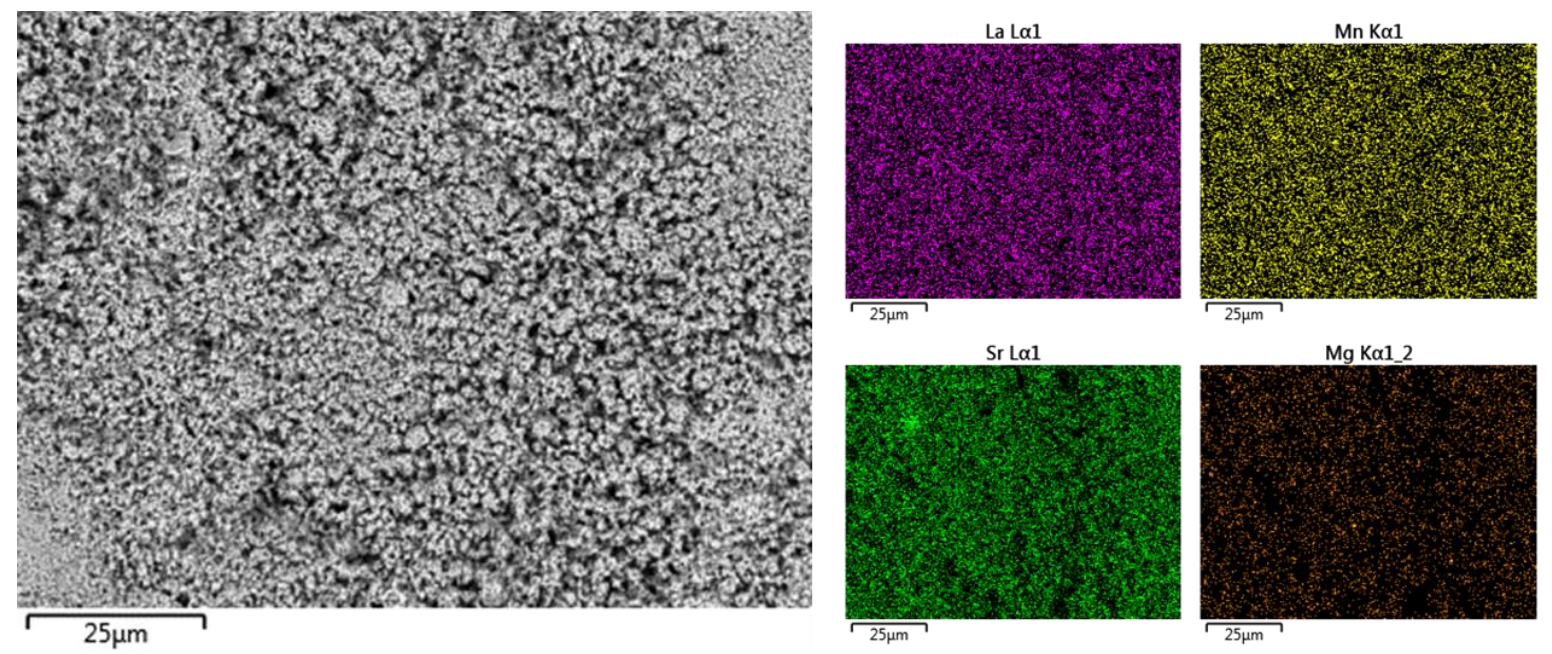

Figure S7: HDBSD image and EDX mapping of LSMMg-P2 powder obtained at $1400{ }^{\circ} \mathrm{C}$. 
Table S1: Composition of $P 1$ and $P 2$ powders series obtained at $1400{ }^{\circ} \mathrm{C}$ (atomic ratio - EDX analysis).

\begin{tabular}{|c|c|c|c|c|c|c|c|}
\hline \multirow{2}{*}{ Sample } & \multirow{2}{*}{ Theoretical formula } & \multicolumn{6}{|c|}{ Atomic \% } \\
\hline & & $\mathrm{La}$ & $\mathrm{Sr}$ & $\mathrm{Mn}$ & $\mathrm{Al}$ & $\mathrm{Mg}$ & $\mathrm{O}$ \\
\hline LSM-P1 & \multirow{2}{*}{$\mathrm{La}_{0.5} \mathrm{Sr}_{0.5} \mathrm{MnO}_{3}$} & 11.6 & 12.3 & 25.6 & & & 50.5 \\
\hline LSM-P2 & & 11.0 & 9.7 & 20.8 & & & 58.5 \\
\hline $\begin{array}{l}\text { LSMAl-P1 } \\
\text { (bright } \\
\text { grains) }\end{array}$ & \multirow{3}{*}{$\mathrm{La}_{0.5} \mathrm{Sr}_{0.5} \mathrm{Mn}_{0.6} \mathrm{Al}_{0.4} \mathrm{O}_{3}$} & 15.5 & 4.6 & 8.8 & 11.6 & & 59.5 \\
\hline $\begin{array}{l}\text { LSMAl-P1 } \\
\text { (dark } \\
\text { grains) }\end{array}$ & & 2.2 & 12.0 & 1.0 & 24.9 & & 59.8 \\
\hline LSMAl-P2 & & 11.0 & 10.2 & 14.6 & 7.5 & & 56.7 \\
\hline LSMMg-P1 & \multirow{2}{*}{$\mathrm{La}_{0.5} \mathrm{Sr}_{0.5} \mathrm{Mn}_{0.9} \mathrm{Mg}_{0.1} \mathrm{O}_{3}$} & 13.1 & 11.6 & 26.0 & & 1.4 & 47.9 \\
\hline LSMMg-P2 & & 13.6 & 9.8 & 22.7 & & 1.9 & 52.0 \\
\hline
\end{tabular}




\section{Calculation method for Mn oxidation state:}

On the premise that the crystallographic structure is globally neutral, it is possible to determine the oxidation degree of Mn ion:

$$
\mathrm{La}_{1-\mathrm{X}}^{3+} \mathrm{Sr}_{\mathrm{X}}^{2+} \mathrm{Mn}_{\mathrm{Y}}^{4+} \mathrm{Mn}_{\mathrm{Y}}^{3+} \mathrm{O}_{3}^{2-}
$$

The sum of each charge is equal to zero and then:

$$
\begin{gathered}
(+3) *(1-\mathrm{x})+(+2) * \mathrm{x}+(+4) * \mathrm{Y}+(+3) * \mathrm{Y}^{\prime}+(-2) * 3=0 \\
\mathrm{Y}+\mathrm{Y}^{\prime}=1 \\
\text { Ox state }(\mathrm{Mn})=\frac{\mathrm{Y} *(+4)+\mathrm{Y}^{\prime} *(+3)}{\mathrm{Y}+\mathrm{Y}^{\prime}}
\end{gathered}
$$

If there is a dopant on the B site (with $y$ rate), the same logic can be used:

$$
\mathrm{Y}+\mathrm{Y}^{\prime}=1-\mathrm{y}
$$

When the perovskite is reduced, the developed formula becomes:

$$
\mathrm{La}_{1-\mathrm{X}}^{3+} \mathrm{Sr}_{\mathrm{X}}^{2+} \mathrm{Mn}_{\mathrm{Y}}^{4+} \mathrm{Mn}_{\mathrm{Y}}^{3+} \mathrm{O}_{3-\delta}^{2-}
$$

and $\delta$ is determined using TGA analysis. 